\title{
José San Román y Rouyer (1901-1961), vida y obra
}

\author{
Concepción CUENCA GONZÁLEZ ${ }^{(1-2)}$ \\ (1) Servicio de Medicina Física y Rehabilitación. Hospital Clínico San Carlos. Madrid. \\ ${ }^{(2)}$ Departamento Medicina Física y Rehabilitación. Hidrología Médica. \\ Facultad de Medicina. Universidad Complutense de Madrid. \\ cuchacuenca@terra.com
}

\begin{abstract}
Resumen
El Profesor San Román, segundo catedrático por orden de sucesión de la Cátedra de Hidrología Médica desde su creación en 1912, fue un luchador infatigable para que la Hidrología Médica ocupara, también en España, un puesto destacado entre las disciplinas de enseñanza obligatoria de la Licenciatura de Medicina y un desarrollo científico a la altura del resto de Europa. Al él se debe la fundación y dirección del Instituto "Alfonso Limón Montero" perteneciente al "Consejo Superior de Investigaciones Científicas" (CSIC) y de su órgano de difusión los Anales Hispanoamericanos de Hidrología Médica y climatología (1954-1959), ambos desaparecidos cuando le sorprendió de forma temprana la muerte, en plena actividad profesional.
\end{abstract}

Palabras clave: José San Román, Cátedra de Hidrología Médica, Instituto de Hidrología Alfonso Limón Montero

José San Román y Rouyer (1901-1961), life and work

\begin{abstract}
Professor San Roman, second professor in order of succession of the Chair of Medical Hydrology since its establishment in 1912, struggled without rest in order to take Medical Hydrology a leading position among the disciplines of obligatory teaching in Medicine and also to make it reach the same level of development that it had already reached the rest of European countries. We owe him the foundation and management of the Institute "Alfonso Limón Montero" that belongs to the "Consejo Superior de Investigaciones Científicas" (CSIC) and also the creation of its organ of diffusion: the Anales Hispanoamericanos de Hidrología Médica y climatología (1954-1959), both of which disappeared when he was surprised by an early death, when he was still in full professional occupation.
\end{abstract}


Key words: José San Román, Chair of Medical Hydrology, Institute of Hydrology Alfonso Limón Montero

REFERENCIA NORMALIZADA

Cuenca C. José San Román y Rouyer (1901-1961), vida y obra. Balnea, 2012, 7, 49-91.

\section{INTRODUCCIÓN}

Con motivo de la conmemoración de los 100 años de la creación de la Cátedra de Hidrología Médica abordo la vida y obra científica del profesor José San Román Rouyer. Para poder conseguir este objetivo de la forma más satisfactoria posible haré referencia a aspectos de su vida personal, tanto de tipo familiar como formativos académicos; a detalles de la época político-social en que le tocó vivir; a su actividad profesional docente, investigadora y creativa, fruto de ella la creación del Instituto "Alfonso Limón Montero" y su órgano de difusión que fue la revista que lleva por título "Anales Hispanoamericanos de Hidrología Médica y Climatología" (AHAHM), así como aspectos ideológicos personales en torno a la tema de la cura balnearia y termalismo social.

La contribución científica del Profesor San Román es, dentro del campo de la medicina, desconocida, incluso dentro del ámbito de la Hidrología Médica. Quizás ello sea debido a la difícil época política en la que le tocó desarrollar su actividad intelectual, a la poca relevancia académica que se le ha dado al estudio de esta especialidad y finalmente, a las tensiones y divisiones existente, durante estos años, entre los propios médicos dedicados al ejercicio asistencial y desarrollo teórico de dicha disciplina. Este ha sido el motivo que me ha impulsado a la realización del presente trabajo: dar conocer a la comunidad científica su merecido puesto de excelencia, en el desarrollo de la Hidrología Médica, a tan incansable trabajador y tenaz figura.

Analizando los antecedentes docentes de la Hidrología Médica en España, encontramos que el estudio de esta especialidad se realizaba en la Licenciatura de Medicina, desde 1866, dentro de la asignatura de "Ampliación de la Terapéutica y Farmacología. Hidrología Médica" En torno al sector extrauniversitario, la docencia consistía, a finales del siglo XIX, en cursos libres impartidos por el Dr. Hipólito Rodríguez Pinilla, figura destacada de esta disciplina ${ }^{1}$.

Posteriormente, con la intención de promover de una forma más intensa la actividad investigadora y la formación teórica se crea en España, por Real Decreto, la primera Cátedra de Hidrología Médica en la Facultad de Medicina de Madrid el 5 de Enero del año $1912^{2}$, si bien dentro de la categoría de libre elección en los estudios de doctorado, siendo designado como responsable de la misma el citado Profesor Hipólito Rodríguez Pinilla. Dicho catedrático, realizó una ardua labor en pro de 
la difusión de esta especialidad desde 1913 hasta su jubilación en 1931 y es en esta época, bajo sus designios, cuando se empieza a fraguar la idea de la creación de un Instituto de Hidrología y Climatología Médica en el que se pudiesen formar los médicos de baños y donde se fomentara la investigación de los efectos beneficiosos y curativos de esta disciplina médica.

En la convocatoria de 1941, la cátedra queda vacante hasta el año 1947, en que por Orden Ministerial, es nombrado Catedrático de Hidrología, en virtud de Oposición, el profesor San Román.

\section{DATOS BIOGRÁFICOS Y ACTIVIDAD CIENTÍFICA: LA CÁTEDRA DE HIDROLOGÍA}

El profesor San Román nace en Portugalete ${ }^{3}$, Vizcaya, el 29 de Junio de 1901. La profesión de su padre era Ingeniero de Minas y este trabajo le exigía desplazarse, en ocasiones, fuera de su lugar habitual de residencia. Pero su infancia se desarrolla fundamentalmente en Madrid, viviendo en régimen de alquiler en una casa perteneciente a Fabiola de Bélgica, en la calle Conde de Xiquena, $\mathrm{n}^{\circ} 15,3^{\circ} \mathrm{D}$.

Cursó estudios de Bachillerato en el Instituto General y Técnico del Cardenal Cisneros, en el año 1916. Durante su periodo formativo, estudió lengua francesa. Ya mientras estudiaba la carrera de Medicina, comienza a despuntar por su gran capacidad de trabajo siendo alumno interno, desde 1919 hasta el 31 de Octubre de 1923, en la Cátedra de Histología, con D. Santiago Ramón y Cajal y en el Departamento de Medicina, con D. Fernando Enríquez de Salamanca, su Maestro. En el Curso Académico de 1921-1922, le conceden el premio "Ribera Sanz". Se graduó en la Facultad de Medicina a los 22 años de edad (Figura 1), obteniendo el Grado de Licenciado el 28 de Septiembre de 1923, con la calificación de sobresaliente. Obtuvo Matrícula de Honor en varias asignaturas como: Patología Quirúrgica y Patología Médica del primer año, Anatomía Topográfica, Historia, Parasitología, Obstetricia, Oftalmología, Medicina Legal y Dermatología. En la asignatura de Hidrología obtuvo calificación de notable 4 .

Comienza su andadura profesional, el mismo año que se licencia. Su inquietud intelectual le empuja hacia el campo de la investigación, comenzando a trabajar en 1923, apadrinado por D. Julián Sanz Ibáñez, Catedrático de Anatomía Patológica, en los laboratorios del Instituto Nacional del Cáncer. A este Instituto seguirá perteneciendo hasta su fallecimiento. Su gran capacidad para el trabajo le permite simultanear el laboratorio con una intensa actividad clínica. Sus salidas al extranjero comienzan en el año 1926, con la visita a la Facultad de Medicina de Buenos Aires. Durante este período realizó la Tesis Doctoral, con el título de "Metabolismo y Rayos X. Modificaciones que experimentan los componentes de la sangre y orina en los cancerosos sometidos a la acción de los Rayos X."; obteniendo el Grado de 
Figura 1 - José San Román y Rouyer - Orla de la Facultad de Medicina de Madrid 1923

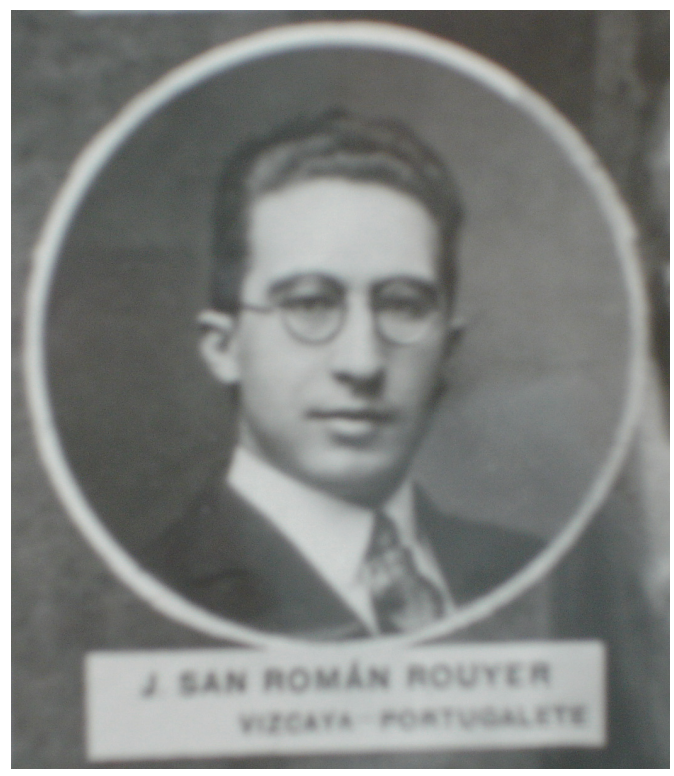

Doctor el 23 de Mayo de 1931, con la calificación de Sobresaliente. En dicha tesis doctoral realiza la siguiente introducción:

"Siempre he supuesto que los rayos X poseían una intensa acción sobre el organismo. Primero, al compás de los estudios y conocimientos del tiempo, se orientó la investigación hacia los efectos locales producidos por las radiaciones de onda corta; luego el microscopio motivó una segunda fase en el estudio de las modificaciones morfológicas; por último los métodos bioquímicos, al perfeccionarse, abrieron un amplio campo.

La intensidad con que el mundo entero trabaja y se investiga hace que, como en todo estudio científico que se inicia, haya siempre precursores.

La acción de los rayos $X$ sobre los procesos orgánicos fue presentida por numerosos autores y ha sido objetivo de diversos estudios experimentales, que vinieron a comprobar de un modo bien patente los profundos efectos de las radiaciones de onda corta. De una parte, la acción directa de la energía radiante sobre la sangre que pasa por la zona radiada; de otra, la acción de los rayos sobre el territorio nervioso y sobre glándulas endocrinas que radiquen dentro de esa misma zona, y, por último, la acción directa de esta energía radiante sobre los tejidos de cualquier clase que sean, y que son atravesados por los rayos $X$, constituyen factores múltiples que pueden explicar los intensos cambios que se dan en el organismo. 
Disponiamos de un arma formidable que la terapéutica utilizaba; pero el no conocer su modo de acción con exactitud motivó un lento progreso en su aplicación y, sobre todo, una escasa difusión como medio terapéutico, pues por tratarse de un método curativo a ciegas, estábamos obligados a ser cautos en su empleo" .

Contrae matrimonio en el año 1935 con Doña Gloria de Terán Fernández (Figura 2), de dicho matrimonio nacieron siete hijos, cinco varones y dos mujeres: José, Juan Manuel, Jesús María, María Ascensión, María Gloría, Carlos y Fernando, tres de ellos profesionales de la Medicina.

Figura 2 - José San Román Rouyer y Gloria de Terán Fernández

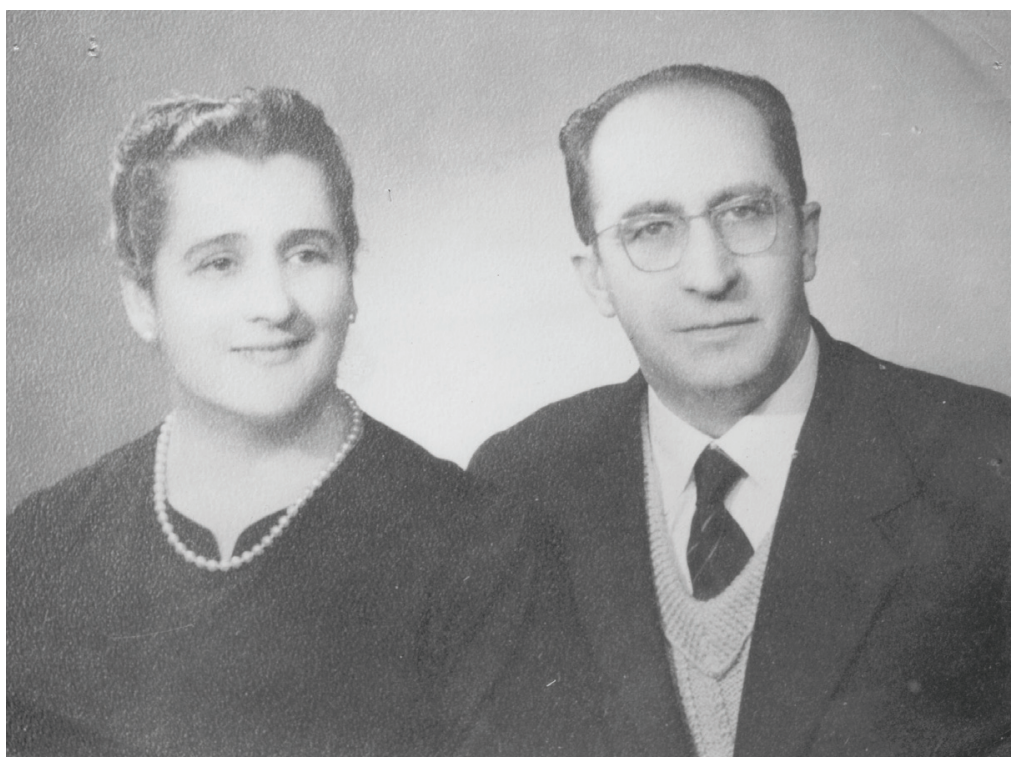

El 18 de julio del año siguiente, desempeñando la Dirección Médica, en calidad de interino en el balneario de Solares (Cantabria), le sorprende junto a su familia, el estallido del Conflicto Civil. Gracias a su ascendencia materna francesa consigue embarcar a Burdeos. No obstante, en el momento en que la situación se lo permite, se incorpora al bando de los sublevados y se traslada con su familia a la ciudad de Valladolid. Durante esta época, su actividad no cesa. No sólo dirige y organiza en esta ciudad un departamento de Cura Balnearia para Heridos y Enfermos de Guerra, en 1938, en la Delegación Nacional de Asistencia a Frentes y Hospitales (no olvidemos que la mayoría de los establecimientos balnearios españoles de ambos bandos, se transformaron en hospitales de guerra), sino que también estuvo al frente del balneario de Zaldívar, confeccionando el listado de los establecimientos balnearios 
que podían ser utilizados por los ejércitos del Norte, Centro y Sur, así como de las principales indicaciones de los mismos según el tipo de afección ${ }^{6}$. Así mismo, publica un libro "Por la higiene de la raza", trabajo no dedicado a la medicina, pero de gran carga ideológica, que le prologa su Maestro el Prof. Fernando Enríquez de Salamanca (Figura 3).

Figura 3 - Por la higiene de la raza - 1938

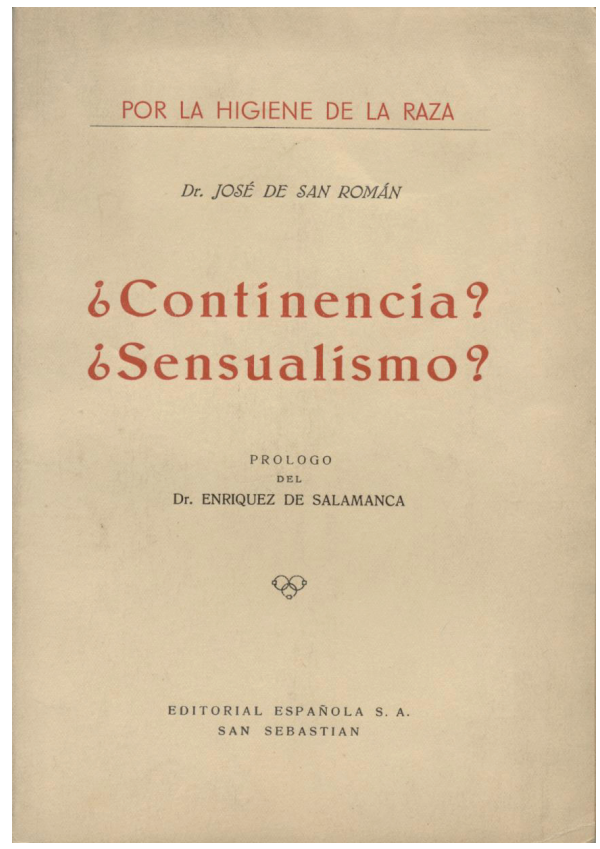

Una valiosísima información nos han aportado los trabajos realizados por San Román, publicados durante los años de la contienda y los más inmediatos a la misma, entre los que destacan los referidos a "La Cura Balnearia en el Ejército. Su aplicación en la guerra y en la post-guerra, 1939", "La Cura Balnearia en la guerra, 1940" y "La Cura Balnearia en el tratamiento de heridos de guerra, 1940"6.

Como hemos señalado anteriormente, durante la Guerra Civil Española, se funda en la Delegación Nacional de Asistencia a Frentes y Hospitales ubicada en Valladolid, un Departamento de Cura Balnearia para Heridos y Enfermos de Guerra, dirigido por el Profesor San Román. En este periodo de tiempo, la organización y dirección de la Sanidad Militar corría a cargo, entre otros, del General Camón y del Coronel Rubio.

Independientemente de los efectos beneficiosos curativos de las aguas mineromedicinales, en un primer momento, gran número de Establecimientos Balnearios 
se transforman en Hospitales de Campaña. No obstante, personas como San Román, destacaron aquellos balnearios que poseían con una clara indicación para el tratamiento de los heridos de guerra y que, atendiendo a la organización militar, correspondían al Ejercito del Norte: los de La Toja, Cuntis, Caldas de Reyes, Arteijo, Lugo, Carballo, Caldas de Orense, Buyeres de Nava, Alceda, Ontaneda, Zaldivar, Molinar de Carranza, Villaro, La Muera, Fitero, Betelú, Elgorriaga, Arnedillo, Paracuellos de Jiloca y Alhama de Aragón; al Ejercito del Centro los de Medina del Campo, Ledesma, Retortillo y Montemayor y al Ejercito del Sur los de Alhama de Granada, Carratraca y Fuente Amarga de Chiclana.

Fruto de éstas gestiones, con fecha 11 de Septiembre de 1938, a propuesta del Inspector General de Sanidad Militar, el "Generalísimo" dispone en un telegrama postal la siguiente orden: "Los enfermos que necesiten hacer uso de aguas medicinales de los establecimientos en que están instalados hospitales miliares podrán solicitar la evacuación individual". Con motivo de esta disposición, el General Meléndez, le solicita al Profesor San Román un proyecto sobre la relación de los balnearios más indicados en el tratamiento de las heridas de guerra y sus secuelas, así como en enfermedades crónicas. Dicho proyecto iba destinado al Ejercito del Norte, distribuyéndose este en dos zonas balnearias: Noroeste en Galicia y Noreste en la Región Vasconavarra.

La relación de Hospitales Militares en funcionamiento en el año 1938, recogidos por el Profesor San Román, situados en Establecimientos balnearios ó en localidades en que existían estos y podían ser utilizadas sus aguas en el tratamiento de los heridos de guerra era:

- Ejercito del Norte: Alhama de Aragón (Zaragoza), Cestona (Guipuzcoa), Fuencaliente (Miranda de Ebro, Burgos), Ontaneda (Santander), Lugo (Capital), Caldas de Orense (Capital), Carballino (Orense), Mondariz (Pontevedra), La Toja (Pontevedra) y Cuntis (Pontevedra).

- $\quad$ Ejercito del Centro: Medina del Campo (Valladolid), Ledesma (Salamanca) y Montemayor (Cáceres).

- $\quad$ Ejercito del Sur: Lanjarón (Granada) y Villaharta (Córdoba).

Confeccionó y remitió a la Inspección General de Sanidad Militar un cuadro con las indicaciones principales de estos balnearios, con el fin de facilitar y orientar, tanto a médicos como enfermos o heridos, sobre la forma de realizar una correcta distribución en dichos hospitales militares, conforme a sus afecciones. Así para los reumatismos en fase subaguda recomienda las aguas de Alhama de Aragón; para heridas tórpidas, anfractuosas, de cicatrización lenta, fístulas, úlceras atónicas, osteítis, osteomielitis, fracturas mal consolidadas, callos óseos viciosos, traumatismos, artritis y reumatismos las de Caldas de Orense, Cuntís, La Toja, Lanjarón, Ledesma, Lugo, Medina del Campo, Montemayor y Ontaneda; para el lavado de las heridas corrientes todas las anteriormente citadas y las de Carbanillo, Cestona y Villaharta; para las anemias las de La Toja, Lanjarón, Mondariz y Villaharta; para las enfermedades del aparato digestivo las de Carbanillo, Fuencaliente, Lanjarón, 
Mondariz, Villaharta y Cestona; para la enfermedades de vías respiratorias las de Alhama de Aragón y Ontaneda y por último, para las enfermedades del aparato urinario las de Fuencaliente, Lanjarón y Villaharta.

En el balneario de Zaldivar, de aguas clorurado-sódicas-sulfurosas, se llevaron a cabo tratamientos de forma ambulatoria, en relación con el Hospital de Basurto, en Bilbao. Los heridos y mutilados eran conducidos desde el hospital para realizar el tratamiento en el balneario y al finalizar las técnicas, tras la toma de agua mineromedicinal, comían antes de regresar de nuevo al hospital. El Ayuntamiento de Zaldivar y la Delegación Local de Frentes y Hospitales, se encargaban de completar con un plato caliente y un café con leche, la comida fría que traían los soldados.

En los balnearios extranjeros, particularmente los alemanes, el número de baños locales solía estar en torno a 30. En este balneario de Zaldivar, se realizaron interesantes estudios sobre la evolución y resultado terapéutico de 21 heridos de guerra, reseñando mejorías importantes en los pacientes tratados. En ningún caso, el número de aplicaciones llegó a superar este número debido principalmente, a lo avanzado de la temporada.

Para tratar a los enfermos de los hospitales militares, situados lejos de los balnearios, con las aguas mineromedicinales en forma de Cura hidropínica, se solicitaron envases al Departamento de Cura Balnearia de la Delegación de Frentes y Hospitales para llenarlos en los establecimientos balnearios y, mediante transportes militares, distribuirlos por mediación del Parque Central Farmacéutico, situado en Valladolid. En 1939, próximo al final de la Guerra Civil, se instaló un hospital militar balneario en el establecimiento de Ontaneda.

Alemania, país de gran desarrollo en aspectos de termalismo, invitó a los Oficiales Españoles heridos en la Guerra Civil, a los establecimientos balnearios de Wiesbaden y Bad Kissingen para su recuperación.

Para la organización de la Cura Balnearia en el Ejército sería muy ventajoso, en opinión del Profesor, la existencia, en cada hospital militar, de una sala ex-profeso para los enfermos sometidos a esta Cura. Las indicaciones que hacía principalmente eran los heridos residuales o los enfermos crónicos, rebeldes a otros tratamientos. La Cura debía hacerse en relación con los hospitales de heridos fijos, de forma ambulatoria o en salas destinados a ellos si el hospital se encontraba en un establecimiento balneario; con los Centros u Hospitales de Residuales y con los Centros u Hospitales de Recuperación Funcional. Estas dos últimas modalidades de Hospitales Militares las ubicaría en los propios establecimientos balnearios, reduciéndose posteriormente el número de camas una vez finalizada la Guerra Civil. Sin embargo, esta propuesta organizativa no llegó a plasmarse tras el término de la misma.

Tras finalizar el conflicto, vuelve a Madrid. Los primeros años de la post-guerra son unos años difíciles. Es a partir de entonces cuando comienza a colaborar como ayudante de clases prácticas en la Cátedra de Hidrología, que se encontraba a cargo de la Doctora $\mathrm{M}^{\mathrm{a}}$ Antonia Martínez Casado ${ }^{8}$, sin percibir dotación económica alguna, hasta que la plaza queda vacante el 19 de enero de 1940 y meses más tarde 
es nombrado, por Orden Ministerial, Auxiliar Temporal, concretamente el 5 de Noviembre de 1940, otorgándosele una gratificación de 3.000 pesetas. Ambos se inscriben a la oposición convocada en 1941 que no llega a celebrarse quedando declarada desierta hasta 1943, siendo los siete candidatos a la misma: José de San Román y Rouyer, Pedro Blanco Cañedo, Juan de Dios García Ayuso, Tomás de Benito landa, García Fernández de la Grinda, Antonia Martínez Casado y Antonio Vila y López. No llegó a presentarse la Dra. Martínez Casado, alegando enfermedad, y solicitando que se retrasase la convocatoria, siendo su petición denegada. El profesor San Román fue el único que llegó hasta el final de los seis ejercicios propuestos.

El 2 de Noviembre de 1943 queda encargado de la Cátedra de Hidrología Médica, durante el curso 1943-1944, percibiendo las dos terceras partes de su sueldo. Por Orden Ministerial de 28 de Diciembre de 1944, es nombrado Profesor encargado del Departamento de Hidrología, durante el curso académico de 1944-1945, con una dotación de 5.000 pesetas. El 12 de Abril de 1944, cesó en percibo de este sueldo "en virtud de lo dispuesto en la Orden Ministerial de 16/3/1944, quedando, por tanto desempeñando la Cátedra como auxiliar que es de la asignatura"".

En 1945 realiza un viaje de estudios a Portugal, a los Institutos de Hidrología Médica de Lisboa, Oporto y Coimbra. En la visita a Lisboa fueron acompañados por el Director del Instituto Profesor Narciso Armando y su ayudante Marqués da Mata. Este viaje será de suma trascendencia pues, a su vuelta, elabora una Memoria con una propuesta para la realización de un proyecto de ampliación de la Cátedra de Hidrología y para la creación, en España, de un Instituto de similares características a las de nuestro país vecino ${ }^{10}$.

En la primera página del prólogo de la Memoria de su viaje a Portugal (1945) se recogen las siguientes líneas:

"Desde que, aún cuando inmerecidamente, hemos ocupado el puesto más elevado en relación con la enseñanza de la Hidrología Médica, creció más, si cabia nuestro entusiasmo y nuestra afición por estos estudios que, bien desarrollados $y$ atendidos, pueden aumentar el prestigio de España en este importante ramo de curar y reportar a nuestro país un considerable beneficio por el cuádruple aspecto del problema balneario; cientifico-médico, industrial, social y sanitario.

Es conocido el auge y la importancia concedida a estas cuestiones en todos los países del mundo. La creación de cátedras de Hidrología en Italia y el extraordinario valor dado en dicho país antes de la Guerra a los problemas sociales balnearios que tan excelentes resultados económicos y curativos ocasionara; la profusión de estudios termales en Francia, a la sombra de sus numerosas cátedras de Hidrología e Institutos Hidrológicos; la imposición en Alemania de la asignatura de Hidrología Médica para todo el que pretenda ejercer la profesión de médico en el país y el esplendor de sus 21 institutos de Hidrología; la atención prestada, incluso por Rusia, a este problema de que sólo puede ser alli supervaloradas las cuestiones materiales y positivistas; en suma, el conocimiento 
de todos los aspectos de la crenoterapia unido a las dificultades de visitar y estudiar en los citados países universidades y balnearios debido al duro desarrollo de la guerra que ha asolado el mundo, hizo que fijáramos nuestra atención en Portugal, país hermano tan afín a nosotros y de cuyo desarrollo hidrológico teniamos escasas referencias."

En Mayo de 1945 salen a concurso-oposición cincuenta plazas de Médicos de Aguas Minero-Medicinales e Inspectores de Establecimientos Balnearios, aprobando y consiguiendo plaza, en el puesto séptimo, de "Digestivo y Reumatismo"11, según se detallan en la Orden de 25 de mayo de 1945 por la que se aprueba el expediente del concurso oposición.

Antes de pertenecer al Cuerpo de Médicos de Baños, desempeñó la Dirección Médica de varios Establecimientos Balnearios. De ésta época, nos consta, estuvo al frente de Chulilla (Valencia), balneario donde se inició y comenzó su interés por este campo de la Especialidad, San Juan de Campos (Baleares) y Solares (Cantabria).

El 30 de Octubre de 1946, el Director General de Enseñanzas Universitarias comunica lo siguiente al Rector: "que de conformidad con la propuesta formulada por el decano de la Facultad de Medicina de Madrid, ha sido elevada por conducto reglamentario. Este Ministerio ha tenido a bien disponer que las cátedras vacantes en dicha facultad de Otorrino, Obstetricia y Ginecología e Hidrología Médica, se encargue provisionalmente durante el presente curso, en tanto subsisten sus nombramientos de Auxiliares Temporales, los Profesores Guillermo Núñez Pérez, José Botella Llusia y José San Román y Rouyer, respectivamente, con los dos tercios del sueldo de entrada en el profesorado, referidos a las dotaciones de las cátedras expresadas y efectos económicos del primero del actual mes de Octubre"12.

Un año más tarde, el 18 de febrero de 1947, se convoca la oposición a la Cátedra de Hidrología Médica de la Facultad de Medicina de la Universidad de Madrid y es nombrado el Tribunal encargado de resolverla. Como presidente se designa a D. Fernando Enríquez de Salamanca y Dánvila (Consejo Superior de Investigaciones Científicas) y como vocales a D. Manuel Bermejillo Martínez (Catedrático de Madrid), D. Valentín Matilla Gómez (Catedrático de Madrid), D. Manuel Armijo Valenzuela (Catedrático de Sevilla) y D. Manuel Vázquez Lefort (Médico Director de Baños). Como presidente suplente se requiere a D. Cesar González Gómez (Consejo Superior de Investigaciones Científicas) y como vocales suplentes a D. Benigno Lorenzo Velásquez (Catedrático de Madrid), D. Arturo Fernández Cruz (Catedrático de Santiago), D. Mariano Mateo Tinao (Catedrático de Zaragoza), y D. Saturnino Mozota (Médico Director de Baños) ${ }^{13}$. Tras la valoración del resto de candidatos, consigue la votación unánime de los cinco miembros del Tribunal y es nombrado Catedrático de Hidrología Médica y Climatología, en virtud de oposición, el 23 de Junio de $1947^{14}$.

El 30 de Junio, el Rector realiza un escrito al Decano notificándole "el nombramiento de D. José San Román y Rouger como Catedrático de Hidrología Médica de 
la Facultad de Medicina de la Universidad de Madrid, con el haber anual de entrada de 12.000 pesetas anuales conforme a lo determinado en la vigente ley de presupuestos y demás ventajas que le conceden las disposiciones vigentes" ${ }^{15}$. A esta actividad dedicó sus mejores esfuerzos. No llegó a trasladarse a la Ciudad Universitaria debido a su prematura muerte, estando prevista su instalación en el Pabellón tercero de la nueva Facultad de Medicina de la Ciudad Universitaria de Madrid, en vecindad a la Cátedra de Farmacología.

Por Orden Ministerial del 6 de Julio de 1950, fue nombrado Secretario de Facultad de Medicina, siendo Decano el Profesor Fernando Enríquez de Salamanca, tomando posesión del cargo el 7 de Julio de 1950, con una gratificación de 4.000 pesetas, y cesando posteriormente del mismo el 9 de Septiembre de $1951^{16}$.

Meses más tarde de tomar posesión de su nuevo cargo de Catedrático, concretamente en Noviembre de 1947, lleva a cabo una de las ideas que durante años venía gestando: la propuesta al Consejo superior de Investigaciones Científicas (CSIC) de la creación de un Instituto de Hidrología Médica y Climatología similar a los que ya existían en otros países europeos como Alemania, Portugal, Francia y Rusia. El Secretario General del CSIC deniega esta petición en Diciembre de este mismo año, pero autoriza la creación de una Sección con el mismo título, encuadrada en el Instituto de Medicina Experimental de Madrid, perteneciente al Instituto Nacional de Ciencias Médicas. En su propuesta, siguiendo la estructura organizativa de otros Institutos de Hidrología Médica de países Europeos y muy probablemente influenciado por los resultados de la documentación obtenida en su viaje a Portugal en el año 1945 (Figura 4), apunta la necesidad de que el Instituto constara de tres secciones ${ }^{17}$.

El Profesor, haciendo honor a su espíritu luchador, no cesa en su empeño, consiguiendo la creación, en Septiembre de 1951, del Instituto "Alfonso Limón Montero", perteneciente al Patronato "Santiago Ramón y Cajal".

Poco después de la fundación del Instituto, aparece la publicación de los Anales Hispano-Americanos de Hidrología Médica y Climatología (Figura 5) que constituyen su órgano de difusión y de los que nos ocupamos por su importancia en otro apartado, viendo la luz el primer número de la revista en el año 1954. Esta publicación se interrumpe en el 1956 debido a la escasez de presupuesto y se reanuda en el 1957 hasta el año 1959, en que finalmente desaparece.

En los Anales, se recogen trabajos realizados en otros países Europeos de la década de los cincuenta como Francia, Alemania y Portugal, de los que sigue muy de cerca los resultados de sus investigaciones, el desarrollo de la actividad hidrológica en sus establecimientos balnearios, Universidades e Institutos de Hidrología y con los que mantiene estrechas relaciones personales e institucionales. De ellos recoge formas de funcionamiento y organizativas para impulsar en España el prestigio de la Hidrología. Prueba de esta inquietud, es la realización de un viaje por Alemania, Italia, Francia y Suiza de un mes de duración en el que conoce a los más eminentes 
crenoclimatólogos de Europa, como el Profesor Justin Besançon y el Profesor Messini y visita afamados balnearios de este momento entre los que esta-

Figura 4 - Propuesta de las relaciones de la Cátedra Hidrología e Instituciones del Estado

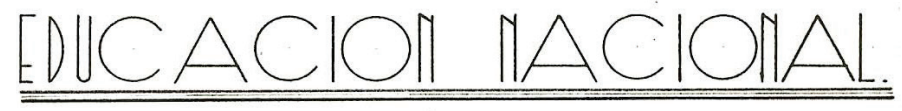

Consejo de Investigaciones Cientificas

Instituto y Catedra de Hidrologia.
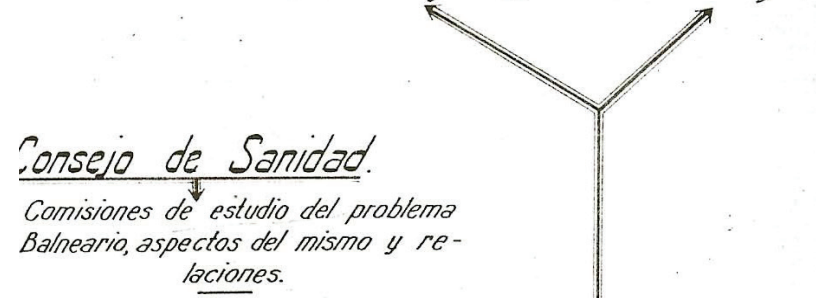

Patronato Macional.

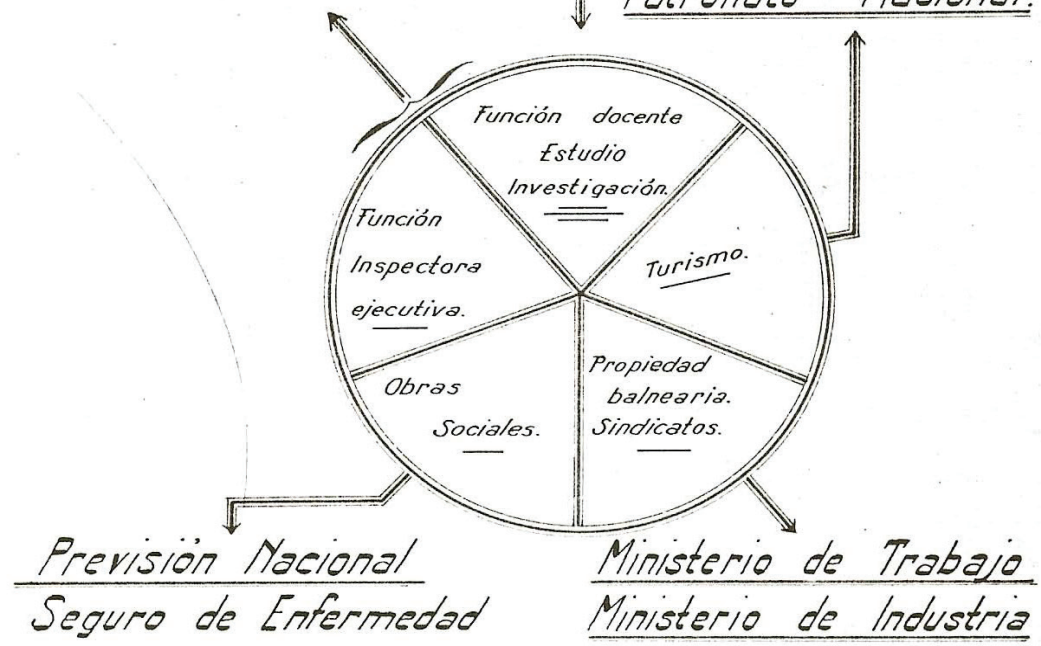

taban los alemanes de Bad Pyrmont, Bad Nauheim, Wiesbaden y Baden-Baden; los franceses de Vichy y Enghien; y los italianos de Rímini, Castrocaro y Montecatini ${ }^{18}$.

Es continuo su interés por la asistencia a congresos tanto nacionales como internacionales, acudiendo al Congreso Internacional de la Sociedad de Hidrología Médica celebrado en Dax en el año 1949. El 24 de Abril de 1953, acepta la invitación del Profesor Mariano Messini, presidente de Asociación Médico-Italiana de 
Hidrología y Talasoterapia al XXXII Congreso Nacional de HidroclimatologíaTalasoterapia y Terapéutica Física, celebrado en Rímini y Castro Caro, los días 12,

Figura 5 - Anales Hispano-Americanos de Hidrología Médica y Climatología. Tomo I

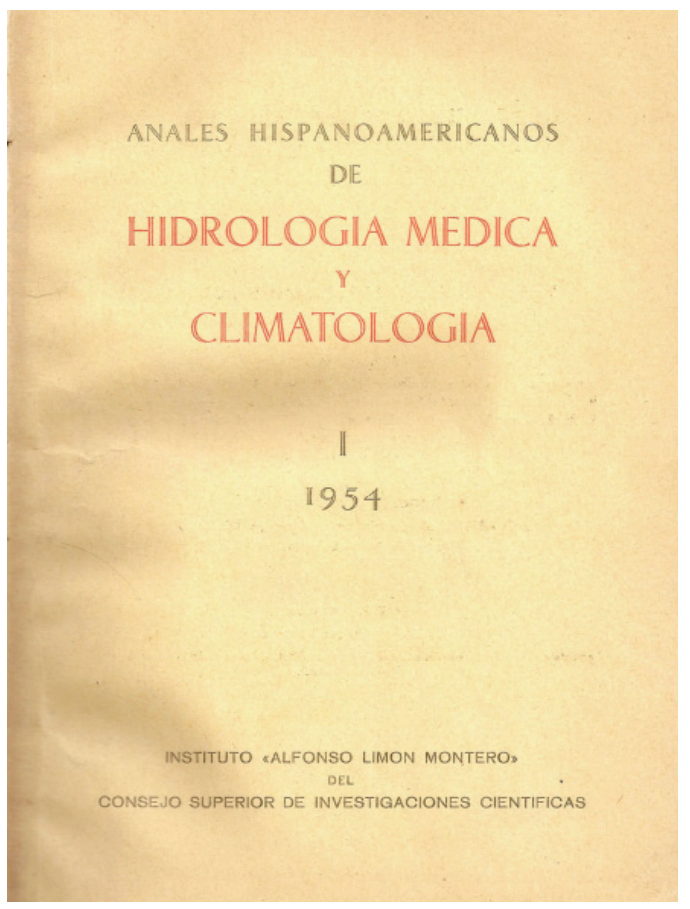

13 y 14 de Junio de 1953. Fue invitado de honor al Congreso Internacional de Termoclimatismo Social, celebrado en Lyón, en Abril del año 1954 y en septiembre de este mismo año, acudió como Delegado Español al Congreso Internacional de Hidrología Médica, celebrado en Vichy - París. Clausuró, en Lisboa, las Primeras Jornadas Luso-Españolas de Hidrología Médica celebradas en Junio de 1958 y es invitado, en 1959, por el Decano de la Facultad de Medicina de la Universidad de Clermon-Ferrand, Francia, para pronunciar la sesión inaugural del curso de verano de ésta Universidad ${ }^{19}$.

Entre sus publicaciones destaca, por su importancia, el libro que lleva por título "Manual de Hidrología Médica" (Figura 6), publicado en el año 1945. Fue premiado por la Real Academia Nacional de Medicina de Madrid y durante más de veinte años fue el manual de referencia de la especialidad en nuestro país ${ }^{20}$. Parte de esta obra, fue recogida textualmente en el "Compendio de Hidrología Médica" del Prof. Armijo Valenzuela ${ }^{21}$. 
Figura 6 - Manual de Hidrología Médica

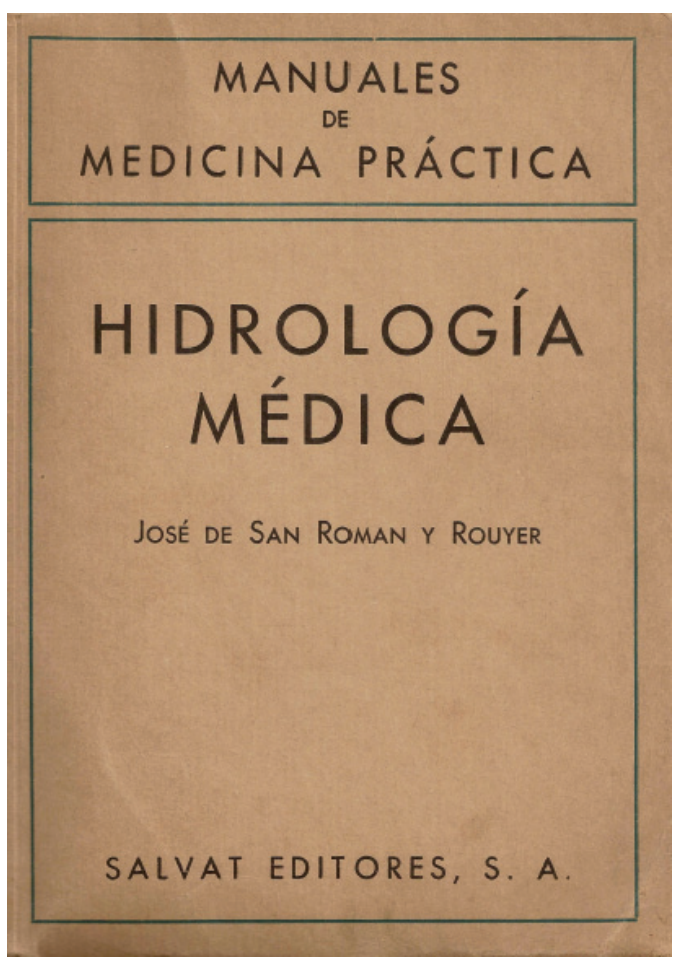

Su prólogo se inicia con las siguientes ideas en torno a la disciplina de la Hidrología Médica:

"Entre las disciplinas que se cursan en nuestras facultades de medicina, siempre existieron algunas especialidades un tanto olvidadas por nuestras juventudes estudiosas y por nuestros médicos especialistas. Entre todas, quizás sea la Hidrología médica la más desconocida, olvidada y descuidad; y se da incluso el hecho tristemente paradójico de ser la cura balnearia, como el tiempo ha de demostrar, uno de los recursos terapéuticos que más interés encierra en el ejercicio de nuestra profesión.

La importancia cada vez mayor que se concedió y se concede a estos estudios en Francia, Alemania, Inglaterra, Italia.... en suma, en tantos países destacados por sus primeros puestos en el progreso de la Medicina, debieron habernos hecho pensar que una rama de la Ciencia Médica cuyo desarrollo desde tiempo inmemorial sigue adquiriendo importancia paso a paso e imponiendo sus doctrinas, que en ocasiones consigue atraer la atención de las primeras figuras de la medicina mundial, tenía que llevar en sí necesariamente una gran parte de 
esa verdad cientifica que se afanan por abracar en su totalidad los investigadores y los sabios en el transcurso de los siglos.

Si fijamos la atención en la Terapéutica hidromineral, podemos apreciar en ella algo (nosotros diríamos lo mejor) de los sistemas médicos que se disputaron el predomino y que trataron de imponer sus doctrinas con un criterio exclusivo en el tratamiento de las enfermedades..."

$\mathrm{Y}$ en su preocupación por el desarrollo y justa consideración de esta especialidad, para dotarla de todo el rigor científico de otras disciplinas médicas, propone la siguiente sistemática de trabajo:

"Hemos comenzado a confeccionar nuestros ficheros, que necesariamente han de resultar incompletos. La labor de recopilación y rectificación de lo existente acerca de nuestras aguas minerales precisa el auxilio y la cooperación de todos los que posean datos y experiencia -sobre estas cuestiones. Por eso, desde nuestra Cátedra de Madrid y en nuestro constante esfuerzo por completar nuestra biblioteca y ficheros, hemos rogado repetidas veces a todos los Directores de baños, médicos hidrólogos, propietarios de balnearios, etc...., que nos remitan folletos, notas de análisis, aguas minerales, lodos, etc.... a fin de continuar nuestra lenta y paciente labor. Sólo entre todos podremos conseguir con el tiempo una perfecta obra de clasificación, especialización, de los manantiales de aguas mineromedicinales españoles.

Lanzamos estas cuartillas con la modesta pretensión de interesar, llamar la atención a la clase médica, para que secunden nuestro esfuerzo y superen así nuestra pobre labor en pro de la Hidrología médica española"

Concluye el prólogo, realizado mientras se encontraba trabajando, durante la temporada balnearia, en Caldelas de Tuy en agosto de 1944, con las siguientes palabras:

"Damos gracias más expresivas por el valioso concurso y ayuda prestado por nuestro ayudante, Adrián Sánchez en la confección de este trabajo, y a nuestros colaboradores Antonio Castillo, Jesús Grinda, Waldo Cardeñosa, y a todos los buenos amigos y compañeros que con su asistencia e interés estimulan nuestro entusiasmo por las cuestiones hidrológicas.

Consideramos cumplido nuestro principal objetivo si contribuimos con un modesto grano de arena a la obra del resurgimiento de la riqueza nacional y al alivio o curación de la humanidad que padece"

El año 1945, publica en el número 15 de la Revista de Geofisica correspondiente a los meses de Julio-Septiembre sus "Conferencias de Radioactividad", pronunciadas en el cursillo de Radioactividad organizado por el Instituto Nacional de Geofísica, que constan de tres conferencias, desarrollándose la primera el 23 de Mayo del citado año. El resumen de los contenidos de la primera dice así:

"Destácase en esta primera conferencia la importancia de la radioactividad en la cura balnearia como uno de los factores más interesantes que explican el poder curativo de las aguas mineromedicinales, en contra de los que por ignoran- 
cia piensan que las curas de aguas tienen sólo una influencia psíquica que, junto con el factor reposo, alimentación, etc.. determinan las acciones sobre el organismo de la hidroterapia en los Balnearios.

Expone ordenadamente la acción de las radiaciones externas e internas que influyen en el organismo y, luego particularmente, las que actúan sobre los átomos y moléculas con sus transformaciones en calor, desplazamiento de electrones, ionización, etc.., teorías que explican modernamente el concepto de óxido reducción.

Las transmutaciones, como fenómenos conseguidos con los bombardeos atómicos y sus sorprendentes desintegraciones, son objeto de un estudio fijo que lleva a conclusiones de sugerentes hipótesis de metabolismo atómico"

En cuanto a su ideología política, comulgaba con las ideas que han venido a denominarse "Nacional-Catolicismo", muy extendidas en la Universidad que le tocó vivir y en la que desarrolló su actividad docente e investigadora ${ }^{22}$. Sin haber estado afiliado a ningún partido, ni sindicato, (aunque simpatizante de la CEDA: Confederación Española de Derechas Autónomas - alianza de partidos políticos fundada el 4 de marzo de 1933, durante el bienio progresista de la II República Española). Hombre de profundas creencias religiosas (miembro de la congregación Adoración Nocturna, de la Hermandad de San Cosme y San Damián, etc.) y de "comunión diaria" como refiere su propia familia ${ }^{23}$ (Figura 7).

Figura 7 - Matrimonio San Román en la Academia de San Dionisio de Jerez de la Frontera, con los doctores de izquierda a derecha: Maraver, Navas, Dañino y Pérez Villa

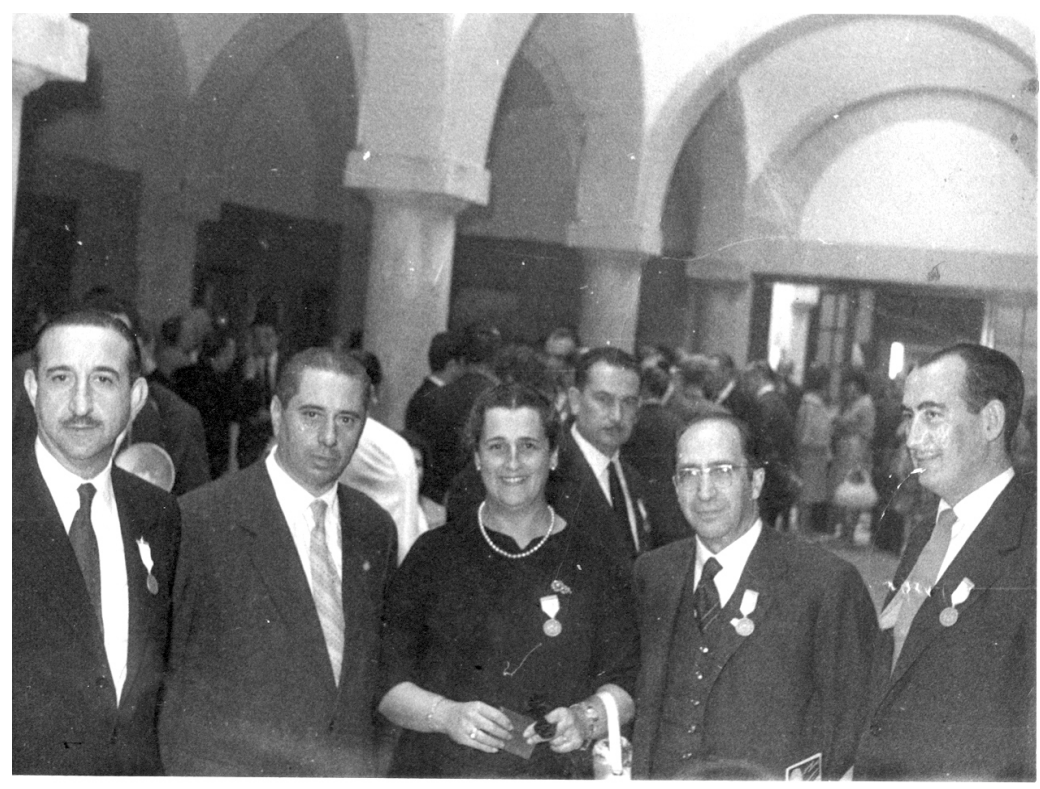


Entre los cargos que ocupó durante su actividad profesional, destacan los de: Inspector Municipal de Sanidad, Médico de la Marina Civil, Médico de la Beneficencia Municipal de Madrid, Profesor del Instituto Nacional de Oncología, Médico Director-Inspector de Aguas Mineromedicinales, Médico de los Ferrocarriles del norte (en todos ellos "por oposición"), Miembro de Honor de la Academia de Ciencias de Bilbao, Miembro de Honor de la Academia de Medicina de Murcia, Directivo de la Sociedad de Hidrología y Climatología Médica, Vicepresidente de la Sociedad Española de Reumatología, Miembro Honorario de la Sociedad Italiana de Hidrología y Climatología Médica, Miembro de la International Society of Medical Hydrology, figurando como Delegado Español de la misma, Catedrático de Hidrología Médica y Climatología en la Universidad de Madrid, desde el año 1947 al 1961, Director del Instituto de Hidrología Médica y Climatología "Alfonso de Limón Montero" perteneciente al Patronato "Santiago Ramón y Cajal" del CSIC y Miembro de la Junta Asesora de Balnearios y Aguas Minero-Medicinales (Dirección General de Sanidad) ${ }^{24}$ (Figura 8).

Como Médico perteneciente al Cuerpo de Baños, desempeñó las direcciones Médicas de los siguientes establecimientos: Caldas de Reyes (Pontevedra), Cadelas de Tuy (Pontevedra), Arteijo (La Coruña), Carballino (Ourense) y Marmolejo (Jaen), pudiendo confirmar más de veinticinco temporadas balnearias ${ }^{25}$.

San Román muere a la temprana edad de sesenta años, en plenitud de su labor intelectual, debido al desenlace fatal de las complicaciones post-quirúrgicas de una enfermedad banal. Llama la atención los múltiples campos, dentro de la Hidrología Médica, que llega a abarcar durante su vida profesional. Su actividad científica docente, investigadora y asistencial se desarrolla, por tanto, desde 1923 hasta 1961, en una España políticamente convulsa; mientras era estudiante, la Monarquía de Alfonso XIII, en sus primeros años de ejercicio profesional, la Dictadura de Primo de Rivera, la Segunda República y el estallido de la Guerra Civil. El resto durante el Franquismo.

Fallece en Madrid el 16 de Enero de 1961. Su cuerpo fue trasladado desde su domicilio, en la Residencia de Profesores de la Ciudad Universitaria, Calle Ministro Ibáñez Martín Número 4, al cementerio de la Almudena, donde fue enterrado. Posteriormente, se celebró un acto religioso en la Capilla de la antigua Facultad de Medicina y en la Sala de Lectura del Decanato de San Carlos una sesión necrológica en recuerdo del que fuera Catedrático de la Facultad de Medicina, en la mañana del día 7 de Febrero de 1961. En ésta, la apertura y clausura fue realizada por el que fuera entonces Decano de la Facultad de Medicina, Benigno Lorenzo Velásquez ${ }^{26}$.

De este acto académico, queda constancia escrita. En él intervienen, además del Decano, sus amigos y compañeros de trabajo los profesores: Antonio Castillo de Lucas, Profesor adjunto de la Cátedra de Hidrología; Valentín Matilla, Catedrático de Microbiología y Parasitología; Guillermo Núñez Pérez, Catedrático de Otorrinolaringología; Alfonso de la Fuente Chaos, Catedrático de patología quirúrgica de la Facultad de Medicina y los también el Padre F. Peiró, Profesor de la Facultad de 
Medicina y José María Alvaro-Gracía Sanfiz, Profesor Adjunto de la Facultad de Medicina y médico del Cuerpo de Baños ${ }^{27}$. Entre las descripciones que hacen de su persona, destacan las de cordial, religioso, modesto, leal y servicial; con simpatía, trabajador tenaz, profesor idealista, maestro; hombre activo, dinámico y apasionado; extrovertido y optimista; rectilíneo en sus juicios y apreciaciones; hombre de su familia y de su casa.

Figura 8 - José San Román Rouyer

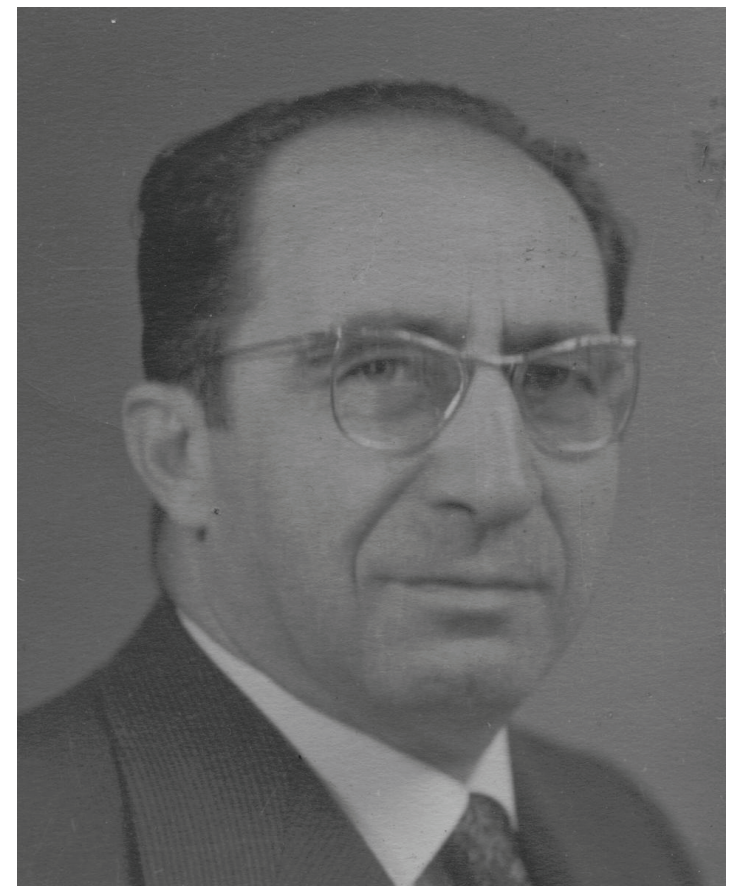

El Profesor Antonio Castillo de Lucas, narra, entre sus anécdotas, que le gustaba pasar lista con frecuencia, no para poner faltas, sino como pretexto para conocer a sus alumnos y poderles llamar luego familiarmente. Dichas faltas eran perdonadas con solo presentar un trabajo experimental o clínico sobre aguas minerales aplicadas a la especialidad que cada alumno cultivara. A finales del curso académico, daba un cursillo de Hidrología por las tardes, especialmente dedicado a aquellos alumnos que no podían haber acudido a clase por las mañanas debido a sus obligaciones $^{28}$.

"Pepe" San Román, nombre con el que coloquialmente le llamaban, gustaba de reunir a todo el personal de la Cátedra en fechas señalas como finales de curso, celebración de su santo y en la aparición de los tomos de los Anales ${ }^{29}$. 
Relata Guillermo Núñez Pérez, Catedrático de Otorrinolaringología: "Raro era el día en que no teníamos una llamada del Profesor San Román ¿Para qué...? ¡Pues no sé exactamente para qué! Porque nada había entre manos, y al separarnos de él teníamos el convencimiento de que lo que quería era ver a sus amigos, charlar con ellos, el calor y la correspondencia de la verdadera amistad ${ }^{430}$.

Entre sus más directos colaboradores encontramos al Dr.Grida, al Dr. Castillo de Lucas y posteriormente, a su hijo Castillo Ojugas. Con el Dr. Grinda organiza el Servicio de Hidroterapia del Ambulatorio "Matías Montero", perteneciente al Seguro Obligatorio de Enfermedad (SOE) y juntos trabajan en el tratamiento y seguimiento de enfermos con dolencias, sobre todo, de tipo reumático y digestivo, ampliando la labor de la Cátedra de Hidrología y las investigaciones del Instituto "Alfonso Limón Montero". Es el Dr. Grinda, el que personalmente se encarga de la formación y preparación del personal subalterno, para la aplicación de masajes e hidroterapia.

San Román poseía un brillante expediente académico, con diez oposiciones ganadas. Fue laureado con el premio "Salgado" por su labor en la Hidrología Médica en el año 1952 y en el año 1959 le conceden una beca de la Fundación Juan March para el estudio de la emanación de radio en las aguas minerales naturales y artificiales. También cosecha el premio "Rodríguez Abaitua"31.

Como recopilación de sus obras más destacadas, destacan: la traducción del libro de Jeanneney, "El Cáncer", de la Editorial Bailly-Bailliere en $1926^{32}$; su Tesis Doctoral "Metabolismo y Rayos X. Modificaciones que experimentan los componentes de la sangre y orina en los cancerosos sometidos a la acción de los Rayos X', $(1931)^{33}$; importante número de artículos en diversas revistas, principalmente de ámbito sanitario, y entre sus libros destacamos su principal obra, del año 1945, ya citada, "Hidrología Médica", libro de referencia para los futuros médicos hidrólogos que se formaban en la Cátedra de Hidrología Médica de la Facultad de Medicina y profesionales en esta materia ${ }^{20}$. La Segunda Edición de este Manual de Hidrología, que estaba preparando en 1960, no llegó a publicarse debido al inesperado fallecimiento de su autor ${ }^{34}$.

Acompaño una relación, por orden cronológico, de sus trabajos principales: "Las aguas del Balneario de San Juan de Campos", Revista Balear de Medicina, julioagosto-septiembre 1927; "Metabolismo y rayos X", Arch Esp Onc, Mayo, 1931; "La Hidrología Médica en Galicia. Medicación radioactiva y clorurada", Anales de la Sociedad Hidrológica y Medicina Latina, 1931; "Contribución al estudio del mecanismo de acción de las radiaciones", Revista Medicina, marzo 1933 (publicado en el libro homenaje a Roffo, Buenos Aires.); "Abandono y desorganización de la cura balnearia en España", Boletín de Medicina, diciembre 1934; "El problema balneario", Boletín de Medicina, enero y abril 1935; "Orientación del problema balneario en España y estudio de la reorganización del Cuerpo de Médicos de Baños", Gaceta Médica Española, julio 1935; "Por la higiene de la Raza. ¿Continencia? ¿Sensualismo?”, Ed. Española, 1938; "Datos de orientación para un pro- 
yecto de Balneario Nacional", Revista de Sanidad e Higiene Pública, marzo-abril 1938, "La Cura Balnearia en el Ejército. Su aplicación en la guerra y en la postguerra", Editorial Científico Médica. Barcelona, 1939; "La Cura Balnearia en la guerra", Semana Médica Española, mayo1940; "La Cura Balnearia en el tratamiento de heridos de guerra", Revista Española de Medicina y Cirugía de la Guerra, julio 1940; "Las Bolsas de Cura de Aguas", Revista de Trabajo, enero 1941; "Aspecto Social de la cura balnearia", Revista Médica, febrero 1941; "La Hidrología experimental y su aplicación en el aparato digestivo", Anales del tercer Congreso Español de Patología Digestiva y de la Nutrición, junio 1941; "Aspecto Social de la cura balnearia en los enfermos del aparato digestivo y nutrición", Anales del tercer Congreso Español de Patología Digestiva y de la Nutrición, junio 1941; "Glucemia y aguas minerales", Anales del tercer Congreso Español de Patología Digestiva y de la Nutrición, junio 1941, "Reorganización de la Cura Balnearia y su aspecto sanitario", Mención honorífica Sociedad de Higiene, 1942; "Algunas notas médicas sobre la Cura Balnearia", Guía Oficial de Balnearios, 1942; "Importancia de la Cura Balnearia", Revista Ferroviarios, febrero 1942; "Ensayos de Hidrología Experimental", Revista Medicina, marzo 1942, "Nuevos aspectos de la Cura Balnearia", Revista Ferroviarios, abril 1942; "Importancia de la Cura Balnearia en los tiempos actuales", Revista Clínica y Laboratorio, Zaragoza, junio 1942; "En torno al problema balneario", Boletín de Colegios Médicos de España, junio 1942; "Un nuevo episodio de examen de las aguas minerales. La microcristalografía aplicada a nuestras aguas", Revista de la Universidad, tomo II, fascículo IV, 1944; “Acción de las radiaciones alfa, beta y gama de los cuerpos radioactivos sobre el intestino aislado de conejo", Anales del IV Congreso Español de Patología Digestiva y de la Nutrición, mayo 1944; "Las aguas minerales españolas y sus efectos sobre el intestino aislado de conejo", Anales del IV Congreso Español de Patología Digestiva y de la Nutrición, mayo 1944; "El problema de la especialización en la Cura Balnearia", Práctica Médica, 15 junio 1944; "Hidrología Médica", Salvat Editores. Primera edición. Barcelona, 1945; "Conferencias de Radioactividad", Revista de Geofísica, núm. 15. Madrid, 1945; "Memoria del viaje de estudios a Portugal", Madrid. 1945; "Nuevos estudios sobre acción biológica y farmacodinámica de la Radioactividad" Madrid, 1946; "Fundamento de la acción de las aguas mineromedicinales radiactivas", Segundo Congreso Hispano-portugués de Hidrología Médica. Madrid, 1950; "Indicaciones de la cura balnearia: principales factores que la condicionan", conferencia pronunciada en junio de 1951, en la reunión médicoquirúrgica internacional de Turín, Ind. Gráficas España, 1952; "Microcristalización o microsedimentación de las aguas minerales y peloides"; en Anales Hispanoamericanos de Hidrología Médica y Climatología (AHAHM). Madrid, 1954; "Modelo guión sobre datos hidroclimáticos, clínicos y experimentales correspondientes a estaciones balnearias", AHAHM. Madrid, 1954; "El agua en bebida ante el concepto de stress. Diuresis, metabolismo y fórmula hemática", AHAHM. Madrid, 1954; "Fundamento de la acción de las aguas mineromedicinales radiactivas". Ponencia 
del Segundo Congreso Hispano-portugués de Hidrología Médica", AHAHM. Madrid, 1954; "La cura balnearia y climática vuelve a destacarse en el mundo científico. Europa reconstruye sus grandes centros balnearios", publicaciones de la Dirección Científica del Instituto Farmacológico Latino, 1954; "Aspecto Social de la Cura Balnearia", AHAHM. Madrid, 1955; "La asistencia de los traumatizados en las estaciones hidro-minerales", AHAHM. Madrid, 1955; "Ensayos sobre los efectos de la Hidroterapia, Crenoterapia y, en especial, de la Cura Radioactiva sobre el eje hipófisis-suprarrenal", AHAHM. Madrid, 1955; "Investigaciones sobre las acciones de la hidroterapia, especialmente con aguas radioactivas, sobre el sistema hipófisis o suprarrenal', Zeitschrift Für Angewandte Bäder-Und Klimaheikkunde. Alemania, 1955; "Fundamentos Científicos de la fisioterapia y particularmente de la Cura Balnearia en el reumatismo", AHAHM. Madrid, 1957; "Las aguas mineromedicinales y los peloides en el tratamiento del reumatismo", AHAHM. Madrid, 1957; "Un ensayo sobre la asistencia a los reumáticos en los balnearios españoles", AHAHM. Madrid, 1957; "Los enfermos de aparato digestivo, particularmente hepáticos, asistidos en Balnearios españoles. Necesidad y beneficios de la clínica balnearia. Exploración de puntos dolorosos", AHAHM. Madrid, 1958 y "Acción paralela del contenido $\mathrm{CO}_{2}$ y de las aguas radioactivas", Bader Und Klimahelkunde. Alemania, 1958.

\section{INQUIETUD POR LA CURA BALNEARIA - EL PROBLEMA BALNEARIO}

Uno de los constantes temas a los que hace referencia San Román en sus publicaciones en las distintas revistas de Medicina es su preocupación por la cura balnearia y lo que se denominaba "el problema balneario". Entre las causas que identifica como responsables de la crisis señala la falta de importancia que se le daba a la Crenoterapia como medio para la profilaxis y curación de las enfermedades, tanto por parte de la clase médica como política, siendo muy pocos los cirujanos y médicos españoles que recurrían a dicha terapéutica balnearia para el tratamiento de sus enfermos ${ }^{35}$.

Entre las propuestas que hace para conseguir el resurgimiento balneario en la España de esta época destacaba el unificar los intereses balnearios; el promover la enseñanza, el estudio, la divulgación y la propaganda entre los pacientes y la clase médica; hacer obligatoria la asignatura de Hidrología Médica en los estudios de Licenciatura; el implicar al Estado en el aprovechamiento de algunos balnearios y el incrementar el interés por el capítulo lúdico de estos establecimientos, que podría resolverse con la afluencia de los propios bañistas a los mismos. Señala la posibilidad de mejorar las comunicaciones para una correcta explotación balnearia y conseguir así el paso de una línea de ferrocarril próxima al establecimiento termal, medio de transporte muy utilizado en la época. También encontramos, entre sus sugerencias, la creación de Ciudades Balneario flotantes de 40.000 ó 50.000 bañis- 
tas, al igual que existían en el resto de los países Europeos, que generaría riqueza y prosperidad a la zona ${ }^{36}$.

Enumera reiteradamente, con apoyo en estudios científicos, los beneficios que aporta la Cura Balnearia como son la curación y profilaxis de enfermedades; la previsión de invalideces; la mejora de la economía para las Cajas de Seguros Sociales; el aumento de la capacidad laboral de los trabajadores; el adelanto y prosperidad que supone para la industria y el comercio; el aumento de los ingresos para el tesoro; el fomento y extensión del turismo; la aportación de divisas; la protección de la autarquía existente en la época; el contacto con los países hispanoamericanos y la curación de los heridos de guerra entre otras ${ }^{37}$.

Responsabiliza del lamentable estado de la Cura Balnearia en España al Cuerpo de Médicos de Baños, lo cual le va a acarrear ciertas enemistades. Pensaba que algunos miembros del Cuerpo no querían jubilarse y esto daba lugar a que no ingresaban médicos nuevos en el Cuerpo de Baños condenándose a una situación de inmovilismo.

Denuncia el tráfico de influencias que existía en la asignación de los balnearios, así como la incompatibilidad del ejercicio de la medicina rural con la de médico de balneario, ya que este trabajo precisa una dedicación exclusiva para ejercer todas las funciones de un buen Director Médico de Baños. En su opinión, eran pocos los que llevaban a cabo algún tipo de labor investigadora y los escasos trabajos realizados eran publicados en revistas de Hidrología Médica, por lo que ésta información no llegaba a otros ámbitos médicos, que desconocían la utilidad y beneficios que reportaban las aguas mineromedicinales. Opinaba que era insuficiente el número de memorias presentadas por los médicos al finalizar la temporada balnearia ${ }^{38}$.

Por otro lado denuncia la existencia de algunas explotaciones clandestinas de manantiales mineromedicinales, que no contaban con ninguna medida higiénica ni con la presencia de médicos prescriptores, con el riesgo que ello conllevaba para los enfermos y sin la declaración de estas irregularidades por parte de los inspectores correspondientes. La labor de inspección en los balnearios, debía de ser realizada por médicos especializados en Hidrología, supeditados a las Autoridades Centrales Sanitarias, con el fin de disponer de libertad de acción y autoridad ${ }^{39}$.

También choca con los intereses de la propiedad balnearia pues propone que sea el Estado el que decida sobre las aptitudes del médico para desempeñar su función en el balneario y no los dueños de los mismos. Una vez demostrada la capacidad del médico, debía de ser el propietario quien tomara la opción de elegir al candidato de mayor conveniencia para él, sin poder ser suprimido de su cargo, salvo por apertura de expediente, disfrutando así de cierta protección frente a cambios de criterio o presencia de un futuro médico entre los familiares de los empresarios.

Con respecto a la especialización de las aguas de nuestros balnearios y de los médicos que en ellos trabajan opina que, en determinadas enfermedades, es complicado realizarlo. Los requisitos indispensables para ello serían un actualizado estudio analítico de las aguas, la creación de un modelo moderno y uniforme de exposición 
de la estadística clínica, la presentación de dicha estadística con el porcentaje de resultados y un estudio detenido de la acción de las aguas mediante la dotación de laboratorios en los establecimientos más relevantes ${ }^{40}$.

Propone la creación de una Corporación o Sindicato, formando por la propiedad balnearia, los médicos de baños, los hoteleros y fondistas de las localidades balnearias, los comerciantes e industriales de las mismas, los empleados, los obreros, así como el personal adscrito a cualquiera de los organismos indicados y cualquier particular interesado en pertenecer a él, para regular todos los asuntos relacionados con la industria balnearia, fomentando, extendiendo y propagando la Cura e Industria Balnearia, tanto en España como en el extranjero. Este Sindicato apoyaría moral y materialmente a sus integrantes en caso de enfermedad, gran número de hijos, vejez e invalidez, organizando Cajas de Socorro, Subsidios, etc. Propone para todos los afiliados al Sindicato el pago de una cuota mensual obligatoria y quizás, proporcional a los ingresos libres que otorgase la industria balnearia a los afiliados al Sindicato, para poder así contar con fondos ${ }^{41}$.

\section{CREACIÓN DEL INSTITUTO “ALFONSO LIMÓN MONTERO”}

El 21 de Noviembre de 1947, el Profesor San Román hace una propuesta para la creación de un Instituto de Hidrología Médica y Climatología al Consejo Superior de Investigaciones Científicas (CSIC). Argumenta la necesidad de la creación en España de un Organismo de similares características a los ya existentes en otros países europeos como Alemania, Portugal, Francia y Rusia, y en otros países del Nuevo Mundo como Cuba y Estados Unidos ${ }^{42}$.

El Instituto debía de relacionarse con la Cátedra de Hidrología Médica para que, en opinión del Profesor, pudieran ser utilizados los recursos que ésta disponía, tales como laboratorios, material, locales y clínica, aminorando así los gastos y colaborando ambos en su desarrollo y mantenimiento. Entre los Organismos que podían aportar sus medios económicos, enumera a los propietarios de Establecimientos Balnearios, a las cuotas de estancia de los bañistas y sus acompañantes, los Organismos Médicos y Sanitarios interesados en problemas médico-sociales tales como el Seguro de Enfermedad, Medicina del Trabajo, los donativos de particulares y empresas y, por último la dotación que el CSIC dedicase a este Instituto ${ }^{43}$.

En su propuesta, el Instituto constaría de tres secciones: Sección de Hidrología Médica, Sección de Climatología y Sección Académica. La primera se dividiría en otras cuatro subsecciones: Estudio de Aguas Mineromedicinales; Hidrología Experimental, cuya labor se desempeñará en los Laboratorios de la Cátedra de Hidrología; Investigaciones Clínicas, en el consultorio clínico, y Prácticas Crenoterápicas. Esta última organizaría viajes de estudios y visitas a los balnearios, sanatorios y manantiales de posible interés médico, estudiaría las aplicaciones hidroterápicas y realizaría investigaciones y estudios en balnearios. Se relacionaría con organizacio- 
nes sociales con los fines de disminuir el paro y la invalidez social, la recuperación funcional y laboral, profilaxis infantil y la lucha contra las plagas sociales (reumatismo, tuberculosis, etc.). La Sección de Climatología se encargaría del estudio de los factores climáticos y climas nacionales y por último, la Sección Académica tendría como objetivos la organización de becas de estudio e investigación, tanto en el extranjero como en los balnearios nacionales; la creación de una biblioteca y un museo, la elaboración de publicaciones y el desarrollo de secciones académicas ${ }^{44}$.

El 29 de Diciembre de 1947, el Secretario General del CSIC, deniega esta petición, pero autoriza la creación de una Sección con el mismo título, encuadrada en el Instituto de Medicina Experimental de Madrid, perteneciente al Instituto Nacional de Ciencias Médicas. El 24 de Mayo de 1948 se acuerda otorgar una gratificación anual de 8.000 pesetas a su Director, Profesor San Román ${ }^{45}$.

El 19 de Septiembre de 1951, en la sesión celebrada en el CSIC, se acordó finalmente crear, el Instituto "Alfonso Limón Montero", en el Patronato "Santiago Ramón y Cajal", con una "dotación de 25.000 pesetas para cada una de las Secciones, dos ó tres de momento" $"$.

El Instituto toma el nombre de "Alfonso Limón Montero", en recuerdo del que fuera Catedrático de Vísperas de Medicina de la Universidad de Alcalá de Henares. Su libro "Espejo Cristalina de las Aguas de España" impreso en 1697, hizo que se le considerara el Padre de la Hidrología Médica Española y bien merece el título del primer Instituto de esta especialidad ${ }^{47}$.

A propuesta del Ministerio de Educación Nacional y previa deliberación del Consejo de Ministros, se dispone:

"Artículo primero: Se crea en Madrid el Instituto de Hidrología Médica y Climatología de "Alfonso de Limón Montero" en el Patronato de Ramón y Cajal dentro del CSIC.

Artículo Segundo: El Instituto tendrá como finalidad la investigación y el estudio de las aguas mineromedicinales y climas Nacionales en todos aquellos aspectos que puedan interesar a la aplicación médica de estos remedios.

Artículo Tercero: tendrá especial establecimiento en Madrid, en relación con la Cátedra de Hidrología Médica y Climatología, centralizará y orientará los estudios crenoclimáticos, procurando su fomento y la creación de centros especializados en otros distritos Universitarios y en Establecimientos Balnearios.

Artículo Cuarto: constará de momento, de dos secciones: una de Hidrología Médica y otra de Climatología. La primera, estará dotada de los siguientes departamentos: a) Estudio de las Aguas Mineromedicinales de la Península, Protectorado y Colonias, b) Hidrología Experimental, C) Investigaciones Clínicas y d) Prácticas Crenoterápicas.

Artículo Quinto: el CSIC dotará al nuevo Instituto de "Alfonso de Limón Montero" de Hidrología Médica y Climatología.

Artículo Sexto: designará el personal investigador el CSIC a propuesta del Instituto". 
El 23 de Mayo de 1952, el Consejo Ejecutivo Superior de Investigaciones Científica acuerda asignar al Profesor San Román la gratificación anual de 15.000 pesetas, que percibirá el primero de Enero del corriente año ${ }^{48}$.

En las Memorias del CSIC de los años 1952-1960, se publican los nombres del Personal Directivo del Instituto "Alfonso Limón Montero". Su Director, desde su creación hasta la desaparición del mencionado Instituto, fue el Profesor José de San Román y Rouyer.

El Instituto, en las memorias del CSIC queda estructurado finalmente en: Sección A, de Estudio de las Aguas Mineromedicinales, dirigida por el Dr. Jesús Aravio-Torre, con la colaboración de Pedro Díez, Augusto Blanco y María de la Iglesia Navarro; la Sección B, de Investigación Clínica y Reumatológica, orientada por el Dr. Jesús Grinda López-Dóriga, con la colaboración de José A. Luque, Guillermo Comba Ezquerra y Antonio Castillo Ojugas y sección C, de Climatología y Meteoropatología, en la que no consta el nombre del Jefe de la Sección en la Memoria de los años 1952-1954, siendo sus colaboradores D. José María Lorente y D. Corpus Munilla $^{49}$. A partir del año 1955, es el propio Profesor D. José de San Román y Rouyer el que se encarga de ella ${ }^{50}$.

Se propone la cuarta planta del tercer pabellón de la Facultad de Medicina de la Ciudad Universitaria para el establecimiento físico de la Cátedra de Hidrología y del Instituto. El presupuesto del proyecto de ejecución de las obras ascendía a la cantidad de dos millones y medio de las antiguas pesetas. Mientras este proyecto se llevaba a cabo, se trasladaron los laboratorios de la Cátedra de Hidrología a las Consultas Públicas de la antigua Facultad de Medicina, ubicada en la calle Atocha 106. Estos locales habían sido asignados por la Dirección del Hospital Clínico San Carlos, para las consultas de Medicina Interna y Reumatología. Los locales del antiguo laboratorio se utilizaron como Biblioteca, Seminario y Fichero. Se tenía previsto adquirir aparataje destinado a las observaciones Meteorológicas y Meteoropatológicas. En el año 1952 y 1953 contaban con un Fichero de un millar de fichas por cada año, duplicando su número en el año $1954^{51}$.

El Profesor San Román y el Dr. Grinda organizan y dirigen los Servicios de Hidroterapia del Ambulatorio Matías Montero, perteneciente al Servicio Obligatorio de Enfermedad (S.O.E.). Sirvieron de excelente recurso para las investigaciones del Instituto y ampliación de la labor de la Cátedra de Hidrología Médica ${ }^{52}$.

Durante los años de actividad del Instituto "Alfonso Limón Montero", se llevó a cabo la realización de múltiples estudios, tanto clínicos como analíticos. Muchos de ellos son el resultado del trabajo en equipo de becarios, colaboradores y profesores.

En el periodo comprendido de 1952 a 1954, se realizan estudios del efecto del agua en bebida y en baño sobre el eje Hipotálamo Hipofisario Suprarrenal mediante determinaciones en sangre de la velocidad de sedimentación, fórmula, recuento globular y eosinofilia y en orina de diuresis, sedimento, relación ácido úricocreatinina y 17 cetosteroides. Se compara la acción del agua destilada, agua potable, agua radioactiva y aguas mineromedicinales embotelladas y a pie de manantial, 
administradas tanto en bebida como en aplicaciones hidroterápicas y en inyecciones hipodérmicas ${ }^{53}$.

El Jefe de la Sección de Estudio de las aguas mineromedicinales, Jesús AravioTorre, analiza las aguas de Tánger, Insalus, Carbanillo, Los Berrazales y Lugo.

Entre los trabajos realizados durante 1955 a 1957, encontramos: La Patera de Otáñez, poder anagotóxico y aguas radioactivas, agua potable y radioactiva en el stress, aguas radioactivas y electrocardiograma, reumatismo: las aguas de Cuntis y la iontoforesis, la asistencia de los traumatizados en las instalaciones hidrominerales, poder catalítico de las aguas minerales sobre el agua oxigenada, análisis de aguas: Daimiel, Ledesma, Betelú, Iturri, trabajos clínicos sobre los baños carbogaseosos y la tensión arterial, estudio de los factores climáticos de las Rias Gallegas, investigación sobre los efectos en sangre y orina de los aerosoles radioactivos, y exploración sobre puntos dolorosos hepáticos en más de 2.000 pacientes seguidos desde la Clínica de Hidrología ${ }^{54}$.

Durante el año 1958, la Sección de Estudio de las aguas minerales realizó un estudio e informe médico sobre las aguas de Dama Iturri (Guipúzcoa) y las aguas de Marmolejo (Jaén), iniciándose la comprobación de las aguas de Pórtugo (Granada). Simultáneamente observan los efectos de los aerosoles con agua radioactiva sobre el ácido úrico en sangre y orina. En los Servicios de Hidroterapia del Ambulatorio "Matias Montero", se analizan los efectos de los distintos recursos hidroterápicos en el eje Hipotálamo Hipófisario Suprarrenal, a través del análisis de los 11-oxi y 17cetosteroides en orina y la eosinofilia. Realizan la determinación de la colestiramina en relación con aguas minerales naturales, artificiales y radioactivas para comprobar la disolución de productos orgánicos. La Sección de Investigación Clínica se encarga de continuar los trabajos iniciados para establecer los porcentajes de puntos dolorosos, directos e indirectos, de 5.000 enfermos de aparato digestivo tratados en el balneario de Marmolejo, rectificando algunos equivocados previamente ${ }^{55}$.

A lo largo del año 1959, se llevan a cabo estudios sobre la acción de la radioactividad de las aguas, colaborando entre otros, Blanco Galdín; Madrid, J; San Román, J. M; Castillo Ojugas; Grinda; De la Iglesia, María; Luque J.A.; San Román, José Alberto y San Juan, Carlos. Analizan los efectos obtenidos sobre pacientes reumáticos y con otras afecciones tras la aplicación de técnicas hidroterápicas en forma de chorros de vapor y agua, baños carbogaseosos, baños con duchas submarinas, etc. Prosiguen los estudios clínicos y reumatológicos de más de 500 enfermos nuevos atendidos en la consulta de la Facultad de Medicina y en el Servicio de Hidroterapia del SOE ubicado en la calle Quintana $\mathrm{n}^{\circ} 11$, en el que se llegó administrar más de 21.000 servicios en el año ${ }^{56}$.

Desde al año 1952 hasta 1960 tenemos referencias de los estudios llevados a cabo por los colaboradores y alumnos becarios del Instituto de Hidrología y Climatología "Alfonso Limón Montero", observándose la gran actividad científicoinvestigadora y la capacidad de trabajo de este equipo. Así recogemos más de una treintena de trabajos, a los que habría que añadir los publicados en los Anales ${ }^{57}$ : 
"Estudios sobre el hierro sérico y eliminación por la leche materna mediante el uso de aguas minerales, medicaciones ferruginosas y emanación radioactiva" de Dña. María de la Iglesia; "Estudios de difusión de la hialuronidasa comparativamente con diversas aguas minerales" y "Acción sobre eliminación biliar en el conejo mediante la inyección intravenosa de aguas minerales" de Dr. Vito Calamita; "Efectos de las aguas de La Toja sobre el eje Hipófisis-Suprarrenal" del Dr. Manuel Moreno de Orbe; "Efectos de la Hidroterapia baño termal sobre cronaxia" de D. Jesús Alonso Carral; "Ascorbinemia en los sujetos tratados con hidroterapia termal" de la Dra. Margarita Guzmán López.; "Crenoterapia de las artrosinovitis reumáticas comprobando también los efectos de la peloidoterapia con lodos de La Toja y Arnedillo como tratamiento de los reumáticos y en secuela de traumatismos y algunos casos clínicos interesantes" de D. Antonio Castillo Ojugas; "Termidas. Salam-bir. Sacedón. La Isabela" del Dr. Castillo de Lucas; "Comportamientos de las aguas mineromedicinales en la recuperación y restablecimiento del equilibrio seroproteico en perros sanos" del Dr. Valle López; "Acciones de algunas aguas mineromedicinales sobre la motilidad de la vena porta" de D. Edesio Gil Tutor; "Acción del agua radioactiva sobre los capilares" de los Dres. García del Puerto y Pinto Díaz; "Influencia del clima y de los factores meteorológicos sobre la mortalidad de Madrid durante los años 1952-1953" de D. Corpus Munilla González; "Ensayos sobre acción de difusión de algunas aguas mineromedicinales españolas" de los Dres. Vito Calamita y Ricci; "Variaciones del glucógeno hepático en animales tratados con aguas sulfurosas" del Dr. Quartuccio; "Germinación, vitalidad y crecimiento en medios hidrológicos mineromedicinales" del Dr. Suárez Ortega; "Balneoterapia en ginecología" del Dr. Hans Baatz; "Nuevos estudios de aguas mineromedicinales españolas" del Sr. Aravio Torres; "Acción de las aguas sulfatado-sódicas y magnésicas sobre el aparato digestivo" del Dr. Perán Torres; "Contribución al estudio de las relaciones entre las funciones hipofisárias y el determinismo de la enfermedad artrósica" del Dr. Bisogno; "Las aguas sulfurosas en el tratamiento de la diabetes" de la Dra. Jimena de la Vega; "La meteorología médica en el noreste de Alemania" del Dr. Lorente; "Sulfatos en la orina y sus modificaciones con la Cura de aguas sulfurosas" del Sr. Orrego; "Ascorbinemia en los sujetos tratados con hidroterapia termal" de la Dra. Guzmán López; "Electroforesis en papel, en sueros de enfermos de la clínica para el estudio de la acción de las aguas minerales y emanación radioactiva sobre los mismos" de la Srta. María de la Iglesia Navarro; "Crenoterapia de las artrosinovitis reumáticas monoarticulares" de Dr. Castillo Ojugas; "Cronaxia y baño termal" del Sr. Alonso Carral; "Aguas Minerales y Radioactivas" de D. José Antonio Luque; "Irrigación Subaqual en Enfermos de Aparato Digestivo" de D. Vicente Navarro; "El Baño Carbogaseoso sobre la Tensión Arterial" de D. José A. San Román; "Poliomielitis, Creatinina en Sangre y Orina y 17 Cetosteroides. Efectos de la Hidroterapia Recuperacional" de D. Carlos San Juan; "Relaciones entre la Ateromatosis de la Aorta y la Artrosis" del Dr. Jesús Grinda.; "La acción de Stress de la ducha subaquática" del Dr. Navarro; "Acción del baño Finlandés sobre la 
fórmula leucocitaria" del Dr. Antonio Fornaza y "Estudio crítico y bibliográfico de la obra de Juan de Dios Ayuda: Examen de las aguas medicinales de más nombre que hay en las Andalucías. Baeza, 1793" del Sr. Castillo de Lucas.

En los años de funcionamiento del Instituto, fueron varias las tesis que se iniciaron, llegándose a concluir la mayor parte de ellas. Recogemos aquí las reflejadas en las Memorias del Centro Superior de Investigaciones Científicas ${ }^{58}$ : "El agua destilada y las aguas mineromedicinales sobre diuresis de líquidos, de sólidos y el presunto estímulo del eje Hipófisis-suprarrenal" de José A. Luque Marcos; “Acción de las aguas en general, especialmente las mineromedicinales y radioactivas sobre el eje Hipófisis-suprarrenal mediante la determinación de la eosinofilia y elemento formes de la sangre" de Augusto Blanco Galdín"; "Influencia del clima y de los factores meteorológicos sobre la mortalidad de Madrid durante los años 1952-1953 con más de 30.000 datos obtenidos” de D. Corpus Munilla González; “Acción de las aguas minerales sobre diversas pruebas funcionales hepáticas" del Dr. Vito Calamita; "Influencia de las aguas minerales y del agua destilada, polarizada y radioactiva sobre el crecimiento de las semillas y sobre la cicatrización de úlceras tórpidas y varicosas mediante la aplicación de lodos de La Toja" del Dr. Suárez Ortega; "Disolución in vitro de cálculos urinarios y sales diversas (fosfatos, carbonatos, oxalatos y uratos) mediante la acción de agua destilada, polarizada, radioactiva y aguas minerales diversas" del Dr. Franco; "Acción anagotóxica de las aguas radioactivas" de D. Juan Torres; "Acción anagotóxica de las aguas medicinales" de D. Francisco Vela y "Acción antianafiláctica de las aguas radioactivas" de D. Roberto Pinto.

Durante los años de existencia del Instituto de Hidrología "Alfonso Limón Montero", fueron varios los congresos científicos nacionales e internacionales en los que participaron sus miembros, especialmente su Director, el Profesor San Román. De todos ellos, enumeramos los recogidos en las Memorias del CSIC $^{59}$ :

- Congreso de la U.I.M.C., celebrado en Madrid, en el año 1952, San Román dio una conferencia sobre "Tratamiento y profilaxia de las enfermedades del aparato circulatorio mediante la Cura Balnearia".

- $\quad$ En 1952, es invitado por la Junta de Cultura de Bilbao, donde habla sobre "Los progresos de la Ciencia en relación con la Cura Balnearia".

- En la Real Academia de Medicina, por su labor realizada en la Hidrología Médica durante el año 1952, fue laureado con el Premio Salgado.

- $\quad$ En Mayo de 1954, se organizó en Madrid, el Primer Congreso de la Sociedad Española de Fisioterapia Reeducativa y Recuperación Funcional. En él, el Profesor San Román, en colaboración con el Dr. Jesús Grinda López Dóriga presentaron una ponencia sobre "Hidroterapia y Recuperación Funcional".

- En el XXXII Congreso de la Asociación Médica Italiana de Hidroclimatología, Talasología y Terapéutica Física celebrado en Rimini-Castrocaro, Italia, en 1953, intervino como socio y huésped de honor y pronunció una Conferencia, cuyo título no se recoge. 
- Fue invitado de honor al Congreso Internacional de Termoclimatismo Social, celebrado en Lyón, en Abril del año 1954. En este Congreso destacó la importancia y trascendencia de la Cura Crenoclimática en el mundo y su orientación social, así como la situación del problema balneario en España.

- $\quad$ En Mayo de 1954, se organizó en Madrid, el Primer Congreso de la Sociedad Española de Fisioterapia Reeducativa y Recuperación Funcional. En él, el Profesor San Román, en colaboración con el Dr. Jesús Grinda López Dóriga presentó una ponencia sobre "Hidroterapia y Recuperación Funcional".

- $\quad$ En Septiembre de 1954, acudió como Delegado Español al Congreso Internacional de Hidrología Médica, celebrado en Vichy, París, donde desarrolló la ponencia "La asistencia a los traumatizados en las estaciones hidrominerales. Organización Social".

- En el mes de Mayo de 1956, en las Jornadas Reumatológicas celebradas en Málaga, participó activamente en colaboración con el Dr. Grinda, Jefe de la Sección de Clínica Reumatológica del Instituto Limón Montero.

- Es invitado a dar una conferencia en la Facultad de Medicina de Sevilla en 1956 y en la Academia de Medicina de Córdoba.

- En la Cátedra de Terapéutica Física, el Profesor San Román, dio cinco conferencias sobre Hidrología a los alumnos de Licenciatura, entre los años 19561957.

- El Profesor San Román clausuró las Primeras Jornadas Luxo-Españolas de Hidrología Médica celebradas en Junio de 1958 en Portugal, con la conferencia: "Algunos nuevos estudios y ensayos en la evolución científica de la Hidrolo-gía".

- El Dr. Grinda, en la XI Jornada Reumatológica, celebrada en Madrid en 1958, presenta la comunicación sobre "La estimuloterapia en Reumatología".

- $\quad$-En las Jornadas Médicas de Jaén en 1958, el Profesor San Román pronunció una conferencia sobre Hidrología Médica.

- Se hace mención al Congreso Internacional de Hidrología Médica de 1958, celebrado en Ischia, Italia, al que sabemos por los Anales, que asistió el Dr. Castillo de Lucas.

- Interviene en el Congreso celebrado por la Federación de Hermandades de San Cosme y San Damián, celebrado en Jérez en 1959, con el tema "Profilaxia y Aguas Minerales".

- En el Congreso de Ortopedia y Recuperación, celebrado en Granada-Málaga, en 1959, participa el Dr. Castillo Ojugas.

- En 1959, es invitado el Profesor San Román, por el Decano de la Facultad de Medicina de la Universidad de Clermon-Ferrand, Francia, para pronunciar la sesión inaugural del curso de verano de ésta Universidad. 
Durante los años de existencia del Instituto de Hidrología "Alfonso Limón Montero", fueron varios los cursos y cursillos que llegaron a organizarse en España. De todos ellos, enumeramos los recogidos en las Memorias del CSIC ${ }^{59}$.

- En 1952, en el Hospital de San Pablo fue invitado a participar en el Curso de Reumatismo, dando una charla sobre "Tratamiento Creno-climático del Reumatismo".

- En el año 1954, el Instituto organizó el Primer Cursillo Intensivo sobre Hidrología Médica y Climatología, en colaboración con la Cátedra de Hidrología Médica.

- Entre los días 14 de Abril a 4 Mayo de 1956, tuvo lugar el Curso Intensivo Teórico Práctico de Clínica Balnearia y de Reumatología, organizado por la Cátedra y el Instituto de Hidrología Médica y Climatología "Alfonso Limón Montero", impartido en la Sala de Grados de la Facultad de Medicina, inaugurado por el Director General de Sanidad, Sr. D. José Palanca y clausurado por el Decano de la facultad de Medicina, Profesor Dr. García López Dóriga ${ }^{60}$.

- Entre los días 14 de Noviembre al 10 de Diciembre de 1957 (Figura 9), se organizó, en colaboración con el Profesor Bermejillo, el Dr. Grinda, y el perso-

Figura 9 - Curso Monográfico de Reumatología organizado por las Cátedras de Patología General e Hidrología y Climatología, patrocinado por la Dirección General de Sanidad

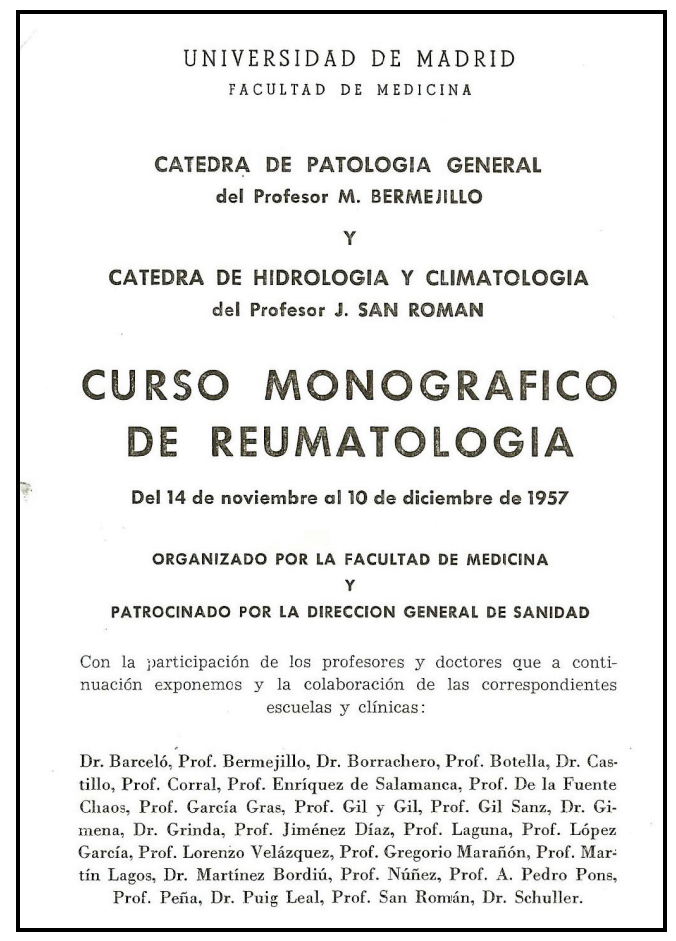


nal del Instituto, con la intervención de diecisiete catedráticos, dos de ellos de Barcelona, el Curso Monográfico de Reumatología teórico práctico y clínico. El curso constaba de sesiones clínicas y prácticas, bajo la dirección del Dr. Grinda, en la consulta y laboratorios de la Cátedra de Hidrología Médica, en horario de once a dos de la mañana y lecciones teóricas. Por las tarde, se realizaban prácticas sobre las últimas técnicas de hidroterapia, peloides, e iontoféresis. Los alumnos que aprobaran, tras finalizar el curso, el examen obtendrían, un certificado de especialización ${ }^{61}$.

- El Profesor San Román, participó en el Curso de Recuperación Funcional organizado por la Dirección General de Sanidad, en 1958.

- $\quad$ En 1958, en la Facultad de Medicina de Madrid, el Profesor San Román organizó un cursillo sobre Cura Balnearia, en el que también intervinieron el Profesor Castillo de Lucas, el Dr. Grinda y el Dr. Castillo Ojugas.

\section{LOS ANALES HISPANOAMERICANOS DE HIDROLOGÍA MÉDICA Y CLIMATOLOGÍA DEL INSTITUTO ALFONSO LIMÓN MONTERO ${ }^{62}$}

El lugar de redacción de los Anales fue en Madrid y el de administración el laboratorio de Hidrología Médica de la Facultad de Medicina, que en aquella época se encontraba ubicada en el número 106 de la calle Atocha. Se intentó que la periodicidad fuera anual desde el año de su creación, en 1954. Sin embargo, se interrumpe en el año 1956 debido a que:

"el importe total de sus presupuestos era insuficiente para costear un tomo más por lo que hubo que retrasar la publicación hasta tener casi liquidada la deu$d a "$

publicándose un tercer y último volumen, en 1959 (Figura 10), que contenía los trabajos de los años 1957 y 1958, desapareciendo definitivamente en esta fecha.

Los lugares de venta de los Anales fueron las principales librerías que daban su servicio en este periodo, y en el propio laboratorio de Hidrología Médica de la Facultad de Medicina. El número de ejemplares impresos es totalmente desconocido.

Desde su inicio, tuvieron una difusión, no solo nacional, sino también fuera de nuestras fronteras, teniendo constancia de su buena acogida en países Hispanoamericanos, así como en países Europeos tales como Alemania, Italia, o Portugal a través de sus Institutos de Hidrología.

En la dedicatoria del primer volumen, San Román refleja sus sentimientos e ilusión por la tarea que inicia:

"A la memoria de mis padres que supieron, con su ejemplo, sembrar en mi vida, desde los primeros años, ideas cristianas y de amor a mi trabajo.

A mi mujer, mi más fiel colaboradora, que con su espiritu de abnegación y sacrificio, sin olvidar su principal misión, me ayuda en mis tareas. 
A vosotros, hijitos, para que recordéis siempre, al ver este modesto libro, los ideales que quiero inculcar en vuestro espiritu: amor a Dios, a España y al trabajo constante, tenaz siempre encauzado hacia vuestra profesión y al alivio de la humanidad que padece"

Figura 10 - Anales Hispano-Americanos de Hidrología Médica y Climatología. Tomo III

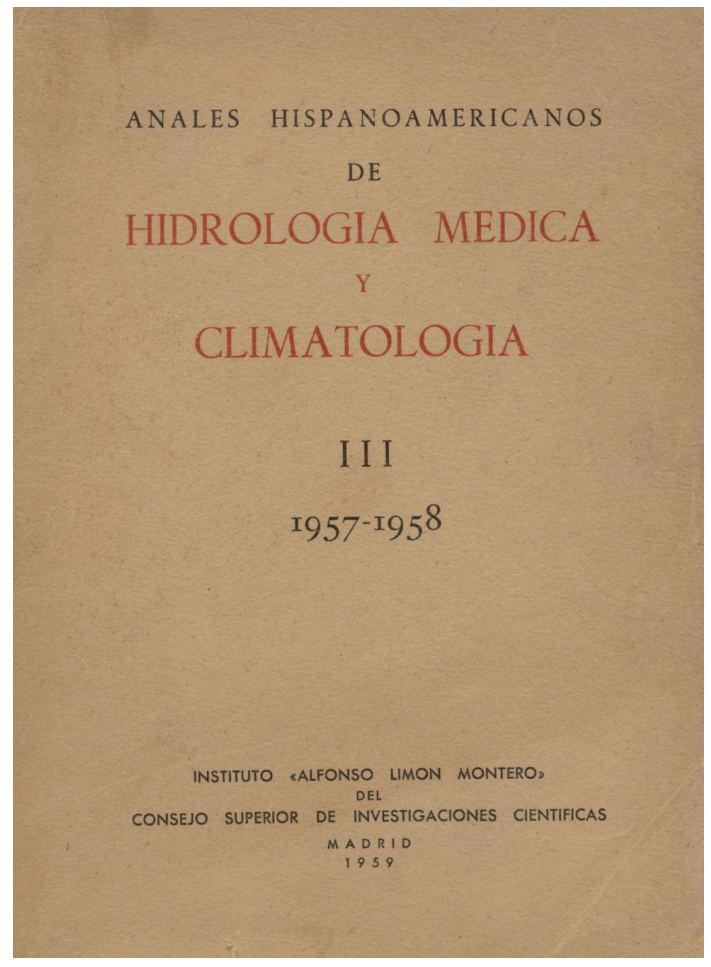

Tres fechas destacan al inicio de los respectivos Anales: la primera, corresponde a una dedicatoria del Jefe del Estado "Generalísimo Francisco Franco", de 20 de Mayo de 1954; la segunda del Sr. D. José Ibáñez Martín, Presidente del Consejo de Estado y fundador del Consejo Superior de Investigaciones Científicas y del primer Instituto Nacional de Hidrología Médica y Climatología, de 11 de enero de 1956, año en el cuál, como ya se ha comentado, no se pudo editar la publicación por falta de presupuesto; y la tercera, de junio de 1959 que corresponde al prólogo del $D r$. G. Marañón, en el cual resume los contenidos del mismo y enumera a los autores de los trabajos científicos, grandes maestros de la reumatología, participantes en el Curso de Reumatología que se recoge el volumen, con un exquisito uso de adjetivos y que dice:

"El benemérito Profesor de Hidrología en la Facultad de Medicina de Madrid y Director del instituto de hidrología Médica y Climatología Alfonso Limón Mon- 
tero, publica ahora, el tomo III de los Anales Hispanoamericanos de esta disciplina, un copioso repertorio de conferencias que patrocinó la Dirección general de Sanidad, sobre el arduo problema de Reumatismo, eterno fantasma que implacablemente nos inquieta a los médicos, pues así lo reclama miles de pacientes doloridos, obligándonos a intervenir en su estudio, harto enfadoso por desairado para el clínico y más aún para el investigador.

Las lecciones que aqui se publican muestran, por de pronto el alto nivel que la preocupación del reumatismo ha alcanzado entre nosotros. Nuestros más eminentes maestros rivalizan en concienzuda información, en vasta habilidad clinica y en agudeza pedagógica para dar al médico actual una conciencia exacta de sus conocimientos en reumáticos. Baste citar el magistral capítulo, el más arduo de todos, sobre Ideas generales sobre el reumatismo y su concepto de y clasificación, obra del Profesor Jiménez Díaz; el perfecto estudio del profesor Corral sobre el tejido conjuntivo; las oportunas consideraciones sobre Etiología de la fiebre reumática, del Profesor Schúller; el acabado examen de El aparato circulatorio en los síndromes reumáticos, del Profesor Bermejillo; la perfecta lección sobre Reumatismos infantiles, del Profesor Laguna; la descripción justa y comprensiva de la artritis reumatoidea, por el Profesor Eloy Gracia López; el resumen tan cínico de la Espondilosis anquilopoyética, del gran especialista catalán Doctor Barceló, lleno de de personal experiencia; el dificil y bien tratado estudio sobre los Pseudo-reumatismos infecciosos, del Puig Leal; el extraordinario, como suyo, Diagnóstico diferencial del reumatismo, del maestro Pedro Pons, tan cásico y tan moderno; la descripción de la Artrosis, llena de sentido clínico, del Doctor, Jesús Grinda; el capitulo exhaustivo de la Gota, por el profesor Gil Sanz; el Reumatismo muscular, perfectamente definido por el Dr. Borrachero del Campo; la muy práctica y elocuente disertación sobre el Hombro doloroso, del Profesor Alfonso de la Fuente Chaos; las eficaces consideraciones de que hace acerca de la Ciática, el Dr. Castillo de Ojugas, al que siguen las dedicadas a la Rodilla dolorosa, por el mismo autor; los Cuadros álgicos de origen endocrino, fina y agudamente descritos por el excelente clínico Doctor Gimena, con ilustraciones bibliográficas que, acaso, se echen de menos en otros capitulos; las complicaciones urológicas reumáticas, brillante expuestas por el Profesor Alfonso de la Peña; la curiosa disertación sobre Gestación y stress, del siempre sagaz Profesor Botella LLusía; el completo y claro estudio sobre la Curación quirúrgica de las cardiopatías reumáticas, por el Doctor Martínez Bordiu; los fundamentos de la Fisiopatología y de la cura Balnearia del Reumatismo, por el Profesor San Román, no hay que decir que acabado; al que sigue, por el mismo autor, el de la Cura hidrotermal del Reumatismo, con el que termina esta prolija pero edificante enumeración.

No tiene esta enumeración el significado de un mero inventario, de un índice más; sino la valoración de un programa que por sí sólo es un total acierto, por la comprensión que revela en la organización del Curso, por parte del Profesor 
San Román, frente al vasto y complejo problema del reumatismo, y la realización perfecta de este programa. Todos sus capitulos son, en efecto, equivalentes en el criterio y, dentro de lo posible, dado el número de colaboradores, uniforme, para que no se turbe la unidad de las lecciones. He pasado varias horas muy gratas y útiles en su lectura y nada de hiperbólico en este juicio: el lector lo comprobara al instante.

La bondad de las doctrinas que se exponen en este libro, demuéstrese singularmente por el hecho de que varias de las conferencias pronunciadas hace ya dos años, y sin embargo, no han perdido actualidad. Nada como esta victoria sobre el tiempo, da la idea del acierto de los escritos científicos y especialmente médicos.

Tendrá, sin duda, este verdadero Tratado sobre Reumatismo una gran difusión y una gran eficacia entre los médicos españoles. Leyéndole se presiente con nostalgia que estos libros de ciencia en los que los autores dejan correr la palabra o la pluma para decir todo lo que sabían, están abocados a un inexorable crepúsculo. Pronto, las conferencias y las lecciones, no tendrán más remedio que ser simples esquemas, sin concesiones retóricas y eruditas. No da más de sí en el porvenir que se echa encima, ni el reloj, ni el incesante crecimiento de los temas, ni el precio de los libros. Y, acaso, éste también de acuerdo con estas exigencias la suprema razón pedagógica"

Como lugar de suscripción, en la contraportada de los mismos, aparece la Librería Científica, situada en la calle Duque de Medinaceli número 4, y también podía realizarse en la Administración, es decir, el Laboratorio de Hidrología Médi$\mathrm{ca}^{63}$ (Figura 11), calle Atocha 106.

Los precios de los diferentes tomos fueron: 75 pesetas en España, para el primer tomo; 75 pesetas en España y 100 pesetas en el extranjero, para el segundo tomo y 150 pesetas en España y 300 pesetas en el extranjero, para el tercero.

El formato de los volúmenes es en hojas de color sepia, cosidas a mano. Están encuadernadas con pastas de papel-tela, color rojo, con impresiones en pan de oro en los lomos. Sus dimensiones son de 236 x $165 \mathrm{~mm}$. El grosor de cada tomo es distinto debido a la variación en el número de hojas de cada uno de ellos.

El número de secciones varía de unos a otros tomos, lo cual hace difícil su agrupación ó clasificación. Entre ellas encontramos: Sección doctrinal, sección histórica, sección experimental, trabajos de alumnos, sección de Clínica y Reumatología, sección de Climatología, intercambio con el extranjero, reseñas de libros, relación de trabajos recibidos, referatas, revistas, congresos y asambleas; cursillos, conferencias y noticias, índice de materias, índice de autores. En el tomo I se recoge, a parte de la introducción y los artículos, cinco secciones, en tomo II, dieciséis secciones y el tomo III está dividido en dos partes: una primera parte que recoge, como ya hemos visto, las conferencias de los maestros de la Clínica y Reumatología en España, que intervinieron en el Curso de Reumatología organizado en la Facultad de Medicina con el Profesor Bermejillo y patrocinado por la Dirección General de 
Sanidad, conteniendo, además de este Curso de Reumatología, cinco secciones; y finalmente, la segunda parte del III tomo, que consta de otras once secciones.

Figura 11 - Laboratorio de Hidrología Médica - antigua Facultad de Medicina de c/Atocha

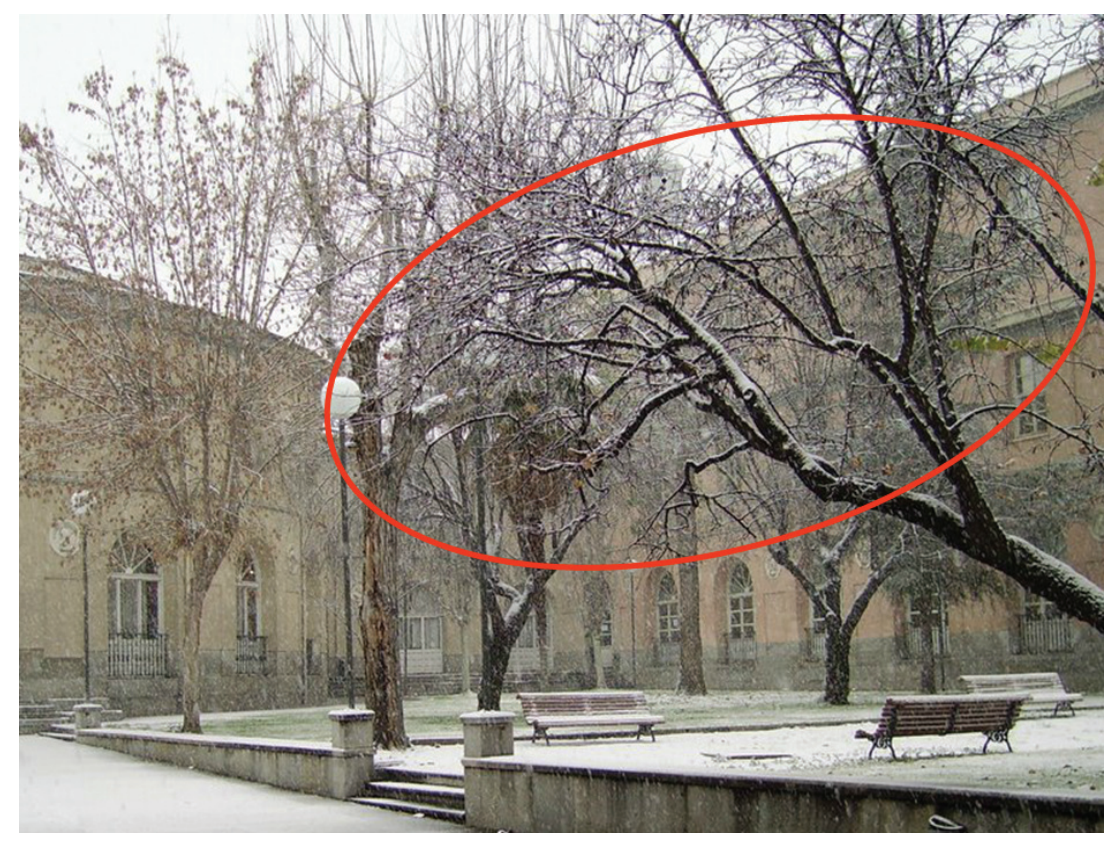

El número de páginas era variable, dependiendo de los tomos. Nos encontramos así con las 395 páginas del tomo I, que es el que menos tiene, 483 del tomo II y 509 del tomo III. Este último fue el más extenso ya que contenía, a diferencia del resto, las publicaciones correspondientes a dos años (1957 y 1958).

El número de láminas tampoco es constante, oscilando entre las diez del tomo III, quince del tomo I y treinta y cinco del tomo II. Algunas de ellas están impresas en color y el resto en blanco y negro. Se recogen cuadros pictóricos y dibujos, fotografías y esquemas, entre otros.

La edición de los Anales se hizo íntegramente en Madrid. Concretamente el tomo I en Gráficas Versal, situada en la calle Jesús del Valle $\mathrm{n}^{\circ} 6$, y los tomos II y III en Industrias Gráficas España, S.L., en la calle Mëjico n ${ }^{\circ} 49$.

El Consejo de Redacción estaba integrado por el Profesor Castillo de Lucas, y los Doctores: Lorente, Grinda, y Aravio Torres, siendo el secretario administrativo en el primer tomo el Doctor Terán Fernández y en el segundo De la iglesia. En el tomo tercero formaban también parte del Consejo de Redacción los Doctores De la Iglesia, Luque, Castillo Ojugas y Blanco.

La introducción de los tres tomos de los Anales está realizada por el Director de la revista Profesor San Román y Rouyer. En ellas se hace una llamada a los Poderes 
Públicos, a la Propiedad Balnearia y a los simpatizantes con la Hidrología para una ayuda económica eficaz en su labor investigadora. Se realiza una propuesta de creación de becas para médicos-alumnos destacados en los centros balnearios para realizar los estudios a pie de manantial. El Profesor San Román nos expone también su deseo de la creación de alguna sección del Instituto de Hidrología Médica y Climatología en alguno de los balnearios de más posibilidades para relacionar los resultados de los trabajos realizados en Madrid, con aguas embotelladas o sólo hidroterapia, con los efectos conseguidos a pie de los manantiales ${ }^{64}$.

En el tomo I del año 1954, se recoge un amplio estudio sobre la vida del Dr Alfonso Limón Montero, autor de la primera obra escrita en España, dedicada exclusivamente al estudio de las aguas medicinales: "Espejo cristalino de las aguas de España, hermoseado y guarnecido, con el marco de variedad de fuentes y baños. Alcalá, 1697', brillantemente realizado por el Doctor Castillo de Lucas. También se publica un resumen de la Tesis Doctoral del Doctor Vito Calamita, uno de los prestigiosos discípulos y colaboradores del Profesor Messini, Director del instituto de Hidrología Médica y Climatología y Catedrático de Clínica y Terapéutica Hidroclimática de Roma. Se recoge del Segundo Congreso Hispano-portugués de Hidrología Médica la ponencia presentada por Profesor San Román sobre el fundamento de la acción de las aguas mineromedicinales radioactivas y la Conferencia sobre el aspecto científico e importancia actual de la Terapia Hidrológica que pronunció en nuestra Facultad el Profesor Mariano Messini en el aula de farmacología ${ }^{65}$.

En el tomo II del año 1955, se expone como se pretende sea la estructuración de la revista en lo sucesivo. La sección de Climatología está dirigida por el meteorólogo Doctor Llorente, la de Clínica y Reumatología por el Doctor Grinda, ayudado eficazmente por el Doctor Castillo Ojugas, doctorado en Bolonia, y la sección de Estudios de Aguas Mineromedicinales por el Doctor Aravio-Torre. Haremos mención a la colaboración de los Profesores Dra. Jimena de la Vega y Dr. Perán, especialistas Crenoterápicos. En este número se publican las Tesis Doctorales del Doctor Corpus Munilla González y del colombiano Carlos A. Suarez Ortega. En la introducción del tomo II San Román hace referencia al Termalismo Social desarrollado en otros países europeos como fórmula para resolver la ausencia de concurrencia de los pacientes a los balnearios, así como para conseguir una cura eficaz y más económica: El enfermo curado, es en opinión del Profesor, el mejor anuncio y la mejor propaganda ${ }^{66}$.

En la primera parte del tomo III de los Anales, de 1957, se publican las conferencias de los maestros de la Clínica y Reumatología de la España de los años cincuenta, que intervinieron en el Curso de Reumatología celebrado en la Facultad de Medicina de Madrid, del 14 de noviembre al 10 de diciembre de 1957, organizado por los Profesores Bermejillo y San Román y que fue patrocinado por la Dirección General de Sanidad. Entre ellos cabe citar a los Profesores: Marañón, Schüler, Laguna, López García, Jiménez Díaz, Barceló, Pons, Gil Sanz, Borrachero del Campo, De la Fuente Chaos, San Román, De la Peña, Botella y los Doctores: Del 
Corral, Grinda, López-Dóriga, Martínez Bordiú, Castillo Ojugas, Gimena, etc. En él se trataron temas como la artritis reumatoide, la espondilitis anquilopoyética, hombro doloroso, ciáticas, rodilla dolorosa, pseudoreumatismos infecciosos y reumatismos infantiles entre otros. El broche final lo pone el Profesor San Román con sus trabajos de la Cura balnearia en Reumatología y las Aguas Mineromedicinales y Peloides en el tratamiento del reumatismo. El prólogo, como se ha mencionado, lo escribe Marañón, en junio de $1959^{67}$. La segunda parte del tomo III, de 1958-1959, recoge los trabajos del Profesor San Román y del Doctor Castillo de Lucas, junto a los de otros autores de la sección Experimental, sobre aspectos de la acción de distintas aguas a nivel del aparato digestivo, hígado y riñón.

\section{COLOFÓN}

Una vez analizada la vida y actividad científica, docente y asistencial del Profesor San Román, no queda más que concluir que fue, en suma, un luchador infatigable, para que la Hidrología Médica ocupara, también en España, un puesto destacado entre las disciplinas de enseñanza obligatoria de la Licenciatura de Medicina y un desarrollo científico a la altura del resto de Europa. Fue el alma del Instituto "Alfonso Limón Montero" y de los "Anales Hispanoamericanos de Hidrología Médica y climatología", ambos desaparecidos cuando le sorprendió la muerte, en plena actividad profesional.

\section{REFERENCIAS}

1. GRANJEL, L.S.: Medicina Española Contemporánea. Salamanca, Ed. Universidad de Salamanca, 1986, 212-213; ARMIJO VALENZUELA, M.: Antecedentes históricos y evolución de la Especialidad, en Capt. I de Hidrología, Fuenlabrada (Madrid), Organización Médica Colegial, 1990, 1-15.

2. RODRÍGUEZ-SÁNCHEZ, J.A.: Antecedentes históricos: La(s) memoria(s) del agua, en Capt. 1 de Las Aguas Minerales en España, Madrid, ITGE, 2001, 1-15; RODRÍGUEZ-SÁNCHEZ, J.A.: La creación de la Cátedra de Hidrología Médica (1912). X Congreso Nacional de Historia de la Medicina. 1996, Málaga, 201-212 y RODRÍGUEZ-SÁNCHEZ, J.A.: Hipólito Rodríguez Pinilla (1860-1936) y las estrategias institucionalizadoras de la Hidrología Médica en España. Balnea, 2012, 7, 13-47.

3. Testimonio de JOSÉ SAN ROMÁN TERÁN. [6 de mayo de 2005].

4. Archivo Histórico de la Universidad Complutense de Madrid (AHUCM): Expedientes Académicos. Caja 626.

5. SAN ROMÁN Y ROUYER, J.: Acción de las radiaciones alfa, beta y gama de los cuerpos radioactivos sobre el intestino aislado de conejo. Anales del 
IV Congreso Español de Patología Digestiva y de la Nutrición. Madrid, Mayo 1944; SAN ROMÁN Y ROUYER, J.: Conferencias de Radioactividad. Revista de Geofísica, núm. 15. Madrid 1945, 503-547 y AHUCM: Op. Cit., Caja 626.

6. SAN ROMÁN Y ROUYER, J.: La Cura Balnearia en el Ejército. Su aplicación en la guerra y en la post-guerra. Congreso Médico Militar celebrado en Castellón de la Plana los días 9, 10 y 11 de Febrero del año 1939, Barcelona, Editorial Científico Médica, 1939, 294-298; SAN ROMÁN Y ROUYER: La Cura Balnearia en la guerra. Semana Médica Española, mayo1940, 588594; SAN ROMÁN Y ROUYER: La Cura Balnearia en el tratamiento de heridos de guerra. Revista Española de Medicina y Cirugía de la Guerra, julio 1940, 26-27 y testimonio de JOSE SAN ROMÁN TERÁN. [6 de mayo de 2005].

7. SAN ROMÁN Y ROUYER: Por la higiene de la Raza. ¿Continencia? ¿Sensualismo?. Valladolid, Ed. Española, S.A., 1938.

8. PÉREZ PEÑA, F.: Antonia Martínez Casado. En Exilio y depuración política (en la Facultad de Medicina de San Carlos. Madrid, Visión Net, 2005, 241.

9. Archivo de la Facultad de Medicina de la Universidad Complutense de Madrid (AFMUCM): Personal Docente. Caja 2.

10. SAN ROMÁN Y ROUYER, J: Memoria del viaje de estudios a Portugal. Madrid, 1945.

11. Orden de $\mathbf{2 5}$ de mayo de $\mathbf{1 9 4 5}$ por la que se aprueba el expediente del concurso oposición convocado por Orden de 20 de marzo de 1944 y modificado por la de 15 de enero de 1945 para proveer cincuenta plazas de Médicos de Aguas Minero-Medicinales, Inspectores de Establecimientos Balnearios y nombrando, en consecuencia, a los señores que se expresan y para cada una de las especialidades que también se detallan. B.O.E., núm. 150, de 3 de junio, 4419.

12. AFMUCM: Op. Cit., Caja 2.

13. Orden de $\mathbf{1 8}$ de febrero de $\mathbf{1 9 4 7}$ por la que se nombra el Tribunal para juzgar la oposición a la cátedra de Hidrología médica de la Facultad de Medicina de la Universidad de Madrid. B.O.E., núm. 62, de 3 de marzo $1947,1531$.

14. Orden de 23 de junio de 1947 por la que se nombra en virtud de oposición, a don José San Román Rouyer Catedrático de la Universidad de Madrid. B.O.E., núm. 225, de 13 de agosto, 4552.

15. AFMUCM: Op. Cit., Caja 2.

16. AFMUCM: Op. Cit., Caja 2.

17. Archivo General Administración (AGA). Educación y Ciencia. Caja 2320 (Legajo 31-10999). 
18. Instituto "Alfonso Limón Montero" (Madrid). Memoria Consejo Superior de Investigaciones Científicas del año 1952-1954. Patronato Santiago Ramón y Cajal de Ciencias Biológicas Médicas. Madrid, 427.

19. Congresos y Asambleas. Anales Hispanoamericanos de Hidrología Médica y Climatología (AHAHM), II, 1955, 439-442; Primeras Jornadas Luso Españolas de Hidrología Médica AHAHM, III, 1959, 502-503 e Instituto de Hidrología Médica y Climatología "Alfonso Limón Montero". Memoria Consejo Superior de Investigaciones Científicas del año 1959: Op. Cit., 119120.

20. SAN ROMÁN Y ROUYER: Hidrología Médica. Barcelona, Salvat Editores, 1945.

21. ARMiJo VAlenZUela, M: Compendio de Hidrología Médica. Barcelona, Ed. Científico-Médica, 1968.

22. LAÍN ENTRALGO, P: La universidad en la vida Española. Madrid, Universidad de Madrid, 1951; FONTAIN, A: Los católicos en la Universidad Española actual. Madrid, Ed. Rilp, 1961; LAÍN ENTRALGO, P: El problema de la Universidad: Reflexiones de Urgencia. Madrid, Cuadernos para el diálogo, 1968; HERNANDEZ SANDOICA, E.: La Universidad Central. En PESET, J. L. et all. "Presente, pasado y futuro de la Universidad española". Madrid, Fundación Juan March, 1985; SANTESMASES, M.J: Entre Cajal y Ochoa. Ciencias Biomédicas en la España de Franco, 1939-1975. Madrid, CSIC, 2001; ALVAREZ COBELAS, J.: Envenenados de cuerpo y alma. La oposición universitaria al franquismo en Madrid (1939-1970). Madrid, Siglo XXI de España Ed., 2004 y CLARET MIRANDA, J: El atroz desmoche. La destrucción de la Universidad Española por el franquismo, 1936-1945. Barcelona, Ed. Crítica, 2006.

23. Testimonio de JOSE SAN ROMÁN TERÁN. [6 de mayo de 2005].

24. Archivo General Administración (AGA). Educación y Ciencia. Caja 2320 (Legajo 31-10999); ALVARO-GRACIA SANFIZ, J.M.: Sesión necrológica en memoria del que fue Catedrático de ésta Facultad de Medicina, D. José de San Román Rouyer celebrada en la sala de lectura del Decanato de San Carlos en la mañana del día 7 de febrero de 1961. Madrid, Talleres Gráficos del C.S.I.C. 1961, 25-26; Instancia al "Premio Obieta" de la Real Academia de Medicina, Madrid, 1945; Instituto "Alfonso Limón Montero" (Madrid). Memoria Consejo Superior de Investigaciones Científicas del año 1960. Patronato Santiago Ramón y Cajal de Ciencias Biológicas Médicas. Madrid 1960, 134-135; Instituto “Alfonso Limón Montero" (Madrid). Memoria Consejo Superior de Investigaciones Científicas del año 1960. Patronato Santiago Ramón y Cajal de Ciencias Biológicas Médicas. Madrid 1962, 13 y testimonio de JOSE SAN ROMÁN TERÁN. [6 de mayo de 2005].

25. ÁLVARO-GRACIA SANFIZ, J.M.: Op. Cit., 25-26 y testimonio con JOSÉ SAN ROMÁN TERÁN [6 de mayo de 2005]. 
26. AGA: Condolencias de José Royo, Secretario General del CSIC. Madrid, 22 de Marzo de 1961. Op. Cit., 26. Leg 31/10999; LORENZO VELÁZQUEZ, B.: Clausura del Acto, en Sesión necrológica en memoria del que fue Catedrático de ésta Facultad de Medicina, D. José de San Román Rouyer celebrada en la sala de lectura del Decanato de San Carlos en la mañana del día 7 de febrero de 1961: Op. Cit., 5 y PEIRÓ, F.: Sesión necrológica en memoria del que fue Catedrático de ésta Facultad de Medicina, D. José de San Román Rouyer celebrada en la sala de lectura del Decanato de San Carlos en la mañana del día 7 de febrero de 196. Op. Cit., 23.

27. CASTILlO De LUCAS, A.: El Dr. San Román. Profesor idealista: Maestro. Op. Cit., 9-12; MATILLA, V.: IN MEMORIAM. Op. Cit., 13-15; NUÑEZ PÉREZ, G.: Op. Cit., 17-18; DE LA FUENTE CHAOS, A.: La lección de un bello morir. Op. Cit., 19-21; PEIRÓ, F.: Op. Cit., 23-24 y ALVARO-GRACIA SANFIZ, J.M.: Op. Cit., 27.

28. CASTILLO DE LUCAS, A.: Op. cit., 1961, 11.

29. CASTILLO DE LUCAS, A.: Op. cit., 1961, 11.

30. NUÑEZ PÉREZ, G.: Op. cit., 1961, 18.

31. AGA: Op. Cit., Caja 2320 (Legajo 31-10999); AHUCM: Op. Cit., Caja 626; ALVARO-GRACIA SANFIZ, J.M.: Op. Cit., 25-26; Instituto "Alfonso Limón Montero" (Madrid). Op. Cit., 1959, 119.

32. JEANNENEY, G.: El Cáncer. Editorial Bailly-Bailliere. Madrid, 1926.

33. AHUCM: Op. Cit., Caja 626.

34. ALVARO-GRACIA SANFIZ, J.M.: Op. Cit., 25-26.

35. SAN ROMÁN Y ROUYER: Nuevos aspectos de la Cura Balnearia. Revista Ferroviarios. Madrid, Abril 1942, 5 y SAN ROMÁN Y ROUYER: Hidrología Médica. Barcelona, Salvat Editores, 1945, 40.

36. SAN ROMÁN Y ROUYER: Abandono y desorganización de la cura balnearia en España. Boletín de Medicina, diciembre 1934, 9; SAN ROMÁN Y ROUYER: Datos de orientación para un proyecto de Balneario Nacional. Revista de Sanidad e Higiene Pública, marzo-abril 1938, 139 y SAN ROMÁN Y ROUYER: Importancia de la Cura Balnearia. Revista Ferroviarios, febrero 1942, 7 .

37. SAN ROMÁN Y ROUYER: Importancia de la Cura Balnearia en los tiempos actuales. Revista Clínica y Laboratorio, Zaragoza, junio 1942, 404405 y SAN ROMÁN Y ROUYER: Hidrología Médica. Barcelona, Salvat Editores, 1945, 40-42.

38. SAN ROMÁN Y ROUYER: El problema balneario. Boletín de Medicina, Abril 1935, 6-18.

39. SAN ROMÁN Y ROUYER: El problema balneario. Boletín de Medicina, Abril 1935, 4-5. 
40. SAN ROMÁN Y ROUYER: EI problema de la especialización en la Cura Balnearia. Práctica Médica, 15 junio 1944, 25-26.

41. SAN ROMÁN Y ROUYER: Datos de orientación para un proyecto de Balneario Nacional. Revista de Sanidad e Higiene Pública, marzo-abril 1938, 139-147.

42. AGA: Proposición al Centro Superior de Investigaciones Científicas del Catedrático de Hidrología Médica y Climatología de la Facultad de Medicina. 21 de Noviembre 1947. Educación y Ciencia. Caja 2320 (Legajo 31-10999).

43. AGA: Op. Cit., Caja 2320 (Legajo 31-10999).

44. AGA: Plano. Op. Cit., Caja 2320 (Legajo 31-10999).

45. AGA: Carta de San Román. 28 de Mayo 1948. Op. Cit., Caja 2320 (Legajo 31-10999).

46. AGA: Carta de San Román, 12 Diciembre 1951. Op. Cit., Caja 2320 (Legajo 31-10999).

47. AGA: Carta de San Román. 1952. Op. Cit., Caja 2320 (Legajo 31-10999).

48. AGA: Carta de San Román. 28 de mayo 1952. Op. Cit., Caja 2320 (Legajo 31-10999).

49. Instituto de Hidrología Médica y Climatología "Alfonso Limón Montero". Memoria Consejo Superior de Investigaciones Científicas del año 1952-1954: Op. cit, 423.

50. Instituto “Alfonso Limón Montero" de Hidrología Médica y Climatología (Madrid). Memoria Consejo Superior de Investigaciones Científicas del año 1955-1957: Op. cit., 363.

51. Instituto de Hidrología Médica y Climatología “Alfonso Limón Montero". Memoria Consejo Superior de Investigaciones Científicas del año 1952-1954: Op. cit, 425-426.

52. Instituto "Alfonso Limón Montero" de Hidrología Médica y Climatología (Madrid). Memoria Consejo Superior de Investigaciones Científicas del año 1955-1957: Op. cit., 365.

53. Instituto de Hidrología Médica y Climatología “Alfonso Limón Montero". Memoria Consejo Superior de Investigaciones Científicas del año 1952-1954: Op. cit., 423, SAN ROMÁN Y ROUYER, J.: El agua en bebida ante el concepto de stress. Diuresis, metabolismo y fórmula hemática. Anales Hispanoamericanos de Hidrología Médica y Climatología. Madrid 1954, 119-194; ARAVIO-TORRE, J y MARTÍNEZ DE MURGUÍA: Revisión, rectificación y nuevos datos analíticos de las aguas minero-medicinales españolas. Anales Hispanoamericanos de Hidrología Médica y Climatología. Madrid 1954, 69-92.

54. Instituto “Alfonso Limón Montero" de Hidrología Médica y Climatología (Madrid). Memoria Consejo Superior de Investigaciones Científicas del año 1955-1957: Op. cit., 363-364 y CASTILLO DE LUCAS: La pátera de Otañes. AHAHM. Madrid 1957-1958, 413-24. 
55. Instituto “Alfonso Limón Montero" de Hidrología Médica y Climatología (Madrid). Memoria Consejo Superior de Investigaciones Científicas del año 1958: Op. cit, 151; GONZALO, H y SABOGAL, F: Acción de las aguas radioactivas, bipolarizadas y minerales en la disolución de los cálculos renales y de la vesícula biliar: AHAHM. Madrid 1957-1958, 425-434; SAN ROMÁN Y ROUYER, J.: Ensayos sobre los efectos de la Hidroterapia, Crenoterapia y, en especial, de la Cura Radioactiva sobre el eje hipófisissuprarrenal. AHAHM. Madrid 1955, 313-324; SAN ROMÁN Y ROUYER, J.: Los enfermos de aparato digestivo, particularmente hepáticos, asistidos en Balnearios españoles. Necesidad y beneficios de la clínica balnearia. Exploración de puntos dolorosos. AHAHM. Madrid 1958, 383-412 y ARAVIO TORRES, J: Estudio de las aguas mineromedicinales españolas. AHAHM. Madrid 1958, 445-468.

56. Instituto "Alfonso Limón Montero" de Hidrología Médica y Climatología (Madrid). Memoria Consejo Superior de Investigaciones Científicas del año 1959: Op. cit., 119; SAN ROMÁN Y ROUYER, J.: Fundamento de la acción de las aguas mineromedicinales radiactivas. Ponencia del Segundo Congreso Hispano- portugués de Hidrología Médica. AHAHM. Madrid 1954, 297-337 y SAN ROMÁN Y ROUYER, J.: Las aguas mineromedicinales y los peloides en el tratamiento del reumatismo. AHAHM. Madrid 1958, 297-316.

57. Instituto de Hidrología Médica y Climatología “Alfonso Limón Montero". Memoria Consejo Superior de Investigaciones Científicas del año 1952-1954: Op. cit., 425; ídem del año 1955-1957: Op. Cit., 364 e ídem del año 1959: Op. Cit., 119.

58. Instituto de Hidrología Médica y Climatología “Alfonso Limón Montero". Memoria Consejo Superior de Investigaciones Científicas del año 1952-1954: Op. cit., 424-425 e Instituto “Alfonso Limón Montero" (Madrid). Memoria Consejo Superior de Investigaciones Científicas del año 1960.: Op. Cit., 135.

59. Instituto de Hidrología Médica y Climatología "Alfonso Limón Montero". Memoria Consejo Superior de Investigaciones Científicas del año 1952-1954. Patronato Santiago Ramón y Cajal de Ciencias Biológicas Médicas. Madrid 1954, 428-429; Instituto “Alfonso Limón Montero” de Hidrología Médica y Climatología (Madrid). Memoria Consejo Superior de Investigaciones Científicas del año 1955-1957. Patronato Santiago Ramón y Cajal de Ciencias Biológicas Médicas. Madrid 1957, 365; Instituto "Alfonso Limón Montero" de Hidrología Médica y Climatología (Madrid). Memoria Consejo Superior de Investigaciones Científicas del año 1958. Patronato Santiago Ramón y Cajal de Ciencias Biológicas Médicas. Madrid 1958, 152 e Instituto "Alfonso Limón Montero" de Hidrología Médica y Climatología (Madrid). Memoria Consejo Superior de Investigaciones Científicas del año 1959. Patronato 
Santiago Ramón y Cajal de Ciencias Biológicas Médicas. Madrid 1959, 119 120.

60. Cursillo intensivo teórico-práctico de Clínica Balnearia y de Reumatología, organizado por la Cátedra y el Instituto de Hidrología Médica y Climatología "Alfonso Limón Montero" del Consejo Superior de Investigaciones Científicas. Universidad de Madrid, Facultad de Medicina, 14 de abril - 4 mayo de 1956, Madrid, Vicente Rico, S.A., 1-6.

61. Curso Monográfico de Reumatología, organizado por la Facultad de Medicina (Cátedra de Patología General y Cátedra de Hidrología Médica y Climatología) y patrocinado por la Dirección General de Sanidad. Universidad de Madrid, Facultad de Medicina, 14 de noviembre - 10 de diciembre de 1957, Madrid, 1-6.

62. CUENCA GONZÁLEZ, C.: Los Anales Hispanoamericanos de Hidrología Médica y Climatología. Indización y juicio crítico (1954-1958) [tesis]. Madrid: Universidad Complutense, 2005.

63. SAN ROMÁN TERÁN, C.: José de San Román y Rouyer 1940-1961. Conmemoración del centenario de la creación de la Cátedra de Hidrología Médica 1912-2012. Facultad de Medicina UCM. Madrid 17 de abril de 2012. [Accedido 15 Oct 2012].Disponible en: http://www.ucm.es/BUCM/med/doc19730.pdf

64. AHAHM, I, 1954, 8-9.

65. Instituto de Hidrología Médica y Climatología "Alfonso Limón Montero". Memoria Consejo Superior de Investigaciones Científicas del año 1952-1954: Op. cit, 426.

66. AHAHM, II, 1955, 7.

67. AHAHM, III, 1957, 13-330. 